\title{
Self-Fulfilling Debt Crises, Revisited
}

\section{Mark Aguiar}

Princeton University, and

Visiting Scholar, Federal Reserve Bank of Philadelphia Research Department

\section{Satyajit Chatterjee}

Federal Reserve Bank of Philadelphia Research Department

\section{Harold Cole}

University of Pennsylvania, and

Visiting Scholar, Federal Reserve Bank of Philadelphia Research Department

\section{Zachary Stangebye}

University of Notre Dame

ISSN: $1962-5361$

Disclaimer: This Philadelphia Fed working paper represents preliminary research that is being circulated for discussion purposes. The views expressed in these papers are solely those of the authors and do not necessarily reflect the views of the Federal Reserve Bank of Philadelphia or the Federal Reserve System. Any errors or omissions are the responsibility of the authors. Philadelphia Fed working papers are free to download at: https://philadelphiafed.org/researchand-data/publications/working-papers.
MP $20-\bigcirc\}$

PUBLISHED

January 2020

REVISED

June 2022 


\section{Self-Fulfilling Debt Crises, Revisited ${ }^{1}$}

\author{
Mark Aguiar \\ Princeton University
}

Satyajit Chatterjee

Federal Reserve Bank of Philadelphia ${ }^{2}$

\author{
Harold Cole \\ University of Pennsylvania
}

\author{
Zachary Stangebye \\ University of Notre Dame
}

May 26, 2022

\footnotetext{
${ }^{1}$ We thank Manuel Amador for numerous discussions and suggestions throughout the process. We also thank seminar and conference participants; our discussants Giancarlo Corsetti, Ramon Marimon, Luigi Paciello, and Vivian Yue; and Fernando Alvarez, Stephen Morris, and Jesse Schreger for helpful comments.

${ }^{2}$ The views expressed here are those of the authors and do not necessarily represent the views of the Federal Reserve Bank of Philadelphia or the Federal Reserve System.
} 


\begin{abstract}
We revisit self-fulfilling rollover crises by exploring the potential uncertainty introduced by a gap (however small) between an auction of new debt and the payment of maturing liabilities. It is well known (Cole and Kehoe, 2000) that the lack of commitment at the time of auction to repayment of imminently maturing debt can generate a run on debt, leading to a failed auction and immediate default. We show that the same lack of commitment leads to a rich set of possible self-fulfilling crises, including a government that issues more debt because of the crisis, albeit at depressed prices. Another possible outcome is a "sudden stop" (or forced austerity) in which the government sharply curtails debt issuance. Both outcomes stem from the government's incentive to eliminate uncertainty about imminent payments at the time of auction by altering the level of debt issuance. An interesting aspect of the novel crisis equilibria is that the government always transacts at prices associated with the most optimistic beliefs. That is, beliefs induce the government to change debt issuances to a level at which prices are invariant to beliefs, even if this means a sharp reduction or increase in equilibrium issuances relative to the best-case scenario. The distortion of debt policy generates a large increase in spread volatility in both a one-period and a multi-period quantitative debt model.
\end{abstract}




\section{Introduction}

Sovereign debt crises involve high spreads and, at the extreme, failed auctions that lead to an inability to service maturing debt. These crises seem only weakly tied to fundamentals and also appear to exhibit some degree of cross-country contagion. A standard approach to understanding these events is to treat them as arising from a self-fulfilling run on sovereign debt; specifically, a failed auction that precipitates an immediate default on maturing debt. The canonical analysis of Cole and Kehoe (2000) formalizes this notion by relaxing the assumption (implicit in Eaton and Gersovitz (1981) and much of the sovereign debt literature) that a government can commit to repay maturing bonds prior to auctioning new bonds. The Cole and Kehoe (2000) model essentially treats the auction and the decision to repay as occurring simultaneously, since the default decision is perfectly predictable given the price of the government debt at the current auction. Moreover, it generates two possible prices for that debt in equilibrium, either the price implied by assuming that upcoming repayments will be made for sure, or the (zero) price implied by assuming that they will not be repaid for sure. As a result, the Cole and Kehoe (2000) model has a fairly limited scope for debt crises; in particular, a crisis always coincides with a zero price and immediate default. Hence, it suggests that an alternative approach is necessary to understand the many real-world crises in which governments successfully auction new bonds but at steeply depressed prices, or in which governments significantly restrict the amount of bonds they issue in order to avoid a failed auction.

To develop this alternative approach, we start by sharpening the focus on the gap in time between a debt auction and the repayment decision for maturing bonds. Participants in sovereign debt auctions understand that the funds raised will be used, at least in part, for near-term interest and principal payments. However, the auction and repayment are distinct events. This asynchronicity opens up the realistic possibility of there being shocks to the government's payoff to default or repayment that are not known at the time of the auction. We show that this uncertainty (which can be arbitrarily small) generates a rich set of self-fulfilling equilibria beyond the two extremes focused on by Cole and Kehoe (2000). Moreover, because these outcomes include successful auctions, the government potentially has an incentive to manipulate quantities to avoid extreme outcomes. We show that there are situations in which a government can avoid a failed auction either by significantly restricting the amount of bonds issued at auction to secure a favorable price, or by issuing larger quantities at fire-sale prices in order to have sufficient cash on hand to cover upcoming liabilities. The additional predictions from this alternative approach conform more readily to many of the important debt crises that we see in the data. 
Our model starts with the familiar Cole and Kehoe (2000) framework in which a coordination failure can lead to a failed auction and subsequent default. ${ }^{1}$ We then extend their framework by assuming that the participants in sovereign debt auctions understand that the funds raised will be used, at least in part, for near-term interest and principal payments and that there is uncertainty about the government's relative payoff between default and repayment. This uncertainty may involve the costs (political or economic) to default or the size of a bailout the government receives from a third party, like the International Monetary Fund or European Union. We show that even if this uncertainty is arbitrarily small, it can lead to a rich set of self-fulfilling debt crises.

To build intuition, assume that the uncertainty is over a random benefit (or cost) of default that is drawn from a distribution with finite support. Also, hold future equilibrium behavior constant. Assume the state variables (the amount of debt due and the endowment) are such that if creditors coordinate on the best possible price at today's auction, the government repays maturing liabilities with probability one; that is, regardless of the realization of the random return to default, the government honors maturing liabilities. However, if creditors coordinate on a price of zero, the government defaults with probability one, as repayment is too painful absent new auction revenue regardless of the realization of the random return to default. The latter scenario is the traditional Cole-Kehoe crisis. Now suppose creditors focus on the intra-period risk, where "intra-period" refers to the gap in time between the auction of new debt and repayment of maturing debt. We show that there also exists an intermediate price that is supported by a threshold for the random return to default. If the random return is higher than this threshold, then the government defaults on maturing debt. If the random return is lower, the government repays. The price at auction is therefore the probability that the random return is lower than the threshold times the best possible price. That is, bond prices, while strictly positive, are discounted to reflect intra-period risk. The concern about intra-period risk is self-fulfilling, as there is a price that can be supported by alternative creditor beliefs that removes all such risk. Moreover, the multiplicity is static in nature - holding constant future beliefs, there are multiple outcomes that can occur at today's auction. Such an intermediate equilibrium price survives even as we take the variance of the intra-period uncertainty to zero.

\footnotetext{
${ }^{1}$ There are two main traditions in the self-fulfilling debt crisis literature: (i) Calvo (1988) and (ii) Cole and Kehoe (2000). The former tradition focuses on the link between prices today and budget sets (and incentives to default) tomorrow. See Lorenzoni and Werning (2013) and Ayres et al. (2015) for recent papers in the Calvo tradition. The Cole and Kehoe (2000) model features multiple pairs of prices and contemporaneous default decisions that satisfy equilibrium conditions, with multiplicity reminiscent of a bank run. Recent papers in this tradition include Conesa and Kehoe (2011) and Aguiar et al. (2015). In an antecedent to this paper, Aguiar and Amador (2013) construct off-equilibrium mixed-strategy prices in a Cole-Kehoe framework to address the possibility of buybacks of long-term debt during a failed auction.
} 
This raises the question of what is the government's best response to such intermediate beliefs at auction. In the canonical rollover crisis, this is never an issue as the government raises zero revenue for any level of debt issuance. However, under the alternative set of beliefs, the government faces a depressed but positive price schedule.

To understand the government's optimal debt issuance, suppose that under the best-case price, the government would issue some amount of debt $B^{*}$. We show under fairly general conditions that when facing a discounted (but not zero) price schedule, the government chooses among two options. The first of these is to sufficiently reduce its borrowing so as to eliminate intra-period uncertainty and generate a price consistent with a zero probability of default in the upcoming settlement. This outcome is a "sudden stop" (or forced austerity), in which the crisis is manifested by a sharp reduction in the amount of debt the government issues. This choice is optimal if the level of maturing debt is relatively low; otherwise, the reduced amount of auction revenue is too small relative to maturing debt to credibly repay with probability one.

The second option is to issue more debt than $B^{*}$. In particular, the government raises a sufficient amount of revenue at auction that it repays maturing debt with probability one. By generating sufficient funds at auction, the government finds it relatively painless to repay immediately maturing bonds, eliminating intra-period uncertainty. However, the higher level of debt issuance raises the probability of default in future periods. Hence, the government trades intra-period certainty for a prolonged period of greater risk going forward. We show that this is indeed preferable to compensating lenders for intra-period risk. In this scenario, the government responds to low prices by borrowing more. This choice is optimal if the level of maturing debt is relatively high.

Note that because of the government's best response, we may not observe intra-period risk playing a direct role along the equilibrium path. Rather, such risk steers the government away from its otherwise optimal debt-issuance policy to a level at which it avoids paying the cost of such risk. If it overissues relative to the best-case benchmark, then the high spreads reflect default risk in future periods, not compensation for intra-period uncertainty. This result is established for small levels of potential intra-period risk. If such risk is sufficiently large, then the government may not have the ability to eliminate all such risk by altering its debt issuance decision. In that case, the intermediate price may become the only possible outcome that can be supported in equilibrium.

The same logic applies if the uncertainty is about the size of a potential bailout at the time of repayment. In particular, there may be a threshold size of bailout that separates repayment from default. If creditors focus on this aspect of the government's decision, such a threshold becomes a self-fulfilling outcome. Hence, uncertainty over bailouts can become 
the central focus of the debt auction. This possible scenario adds an interesting perspective to the events in Europe around the 2010-2012 debt crises.

The gap in time between auctions of new debt and scheduled repayments, regardless of how short, lies at the heart of our model as well as many real life debt crises. As motivation, consider the canonical rollover crisis of Mexico. The Mexican government entered 1995, having just devalued the peso to stem the sudden reversal in credit inflows and the loss of international reserves. ${ }^{2}$ This was coupled with a significant share of short-term dollarindexed bonds (tesobonos) coming due. In the first quarter of 1995, the government had only $\$ 8$ billion in foreign reserves, while nearly $\$ 10$ billion in tesobono debt was due to mature in the first quarter and an additional $\$ 19$ billion before the end of 1995 . Tesobono auctions were occurring weekly, and by early January 1995 it became clear that creditors were hesitant to purchase enough bonds to roll over maturing debt. The Clinton administration's initial proposed response met resistance from the U.S. Congress, adding to the uncertainty. By the end of January, the administration had successfully circumvented the need for Congressional approval and teamed up with international financial institutions to rescue Mexico. This crisis dynamic is captured in our environment by modelling creditors - at the time of an auction - as uncertain about whether the government can raise sufficient funds from a third party to cover any shortfall due to a potentially under-subscribed auction.

This concentration of maturity and rapid sequence of events as the crisis worsened seems quite common. Similar sequences of events played out in the European crisis of the 2010s. For example, Portugal had financing needs of 56.5 billion euros in 2011, nearly 30 billion of which was maturing debt. The government was able to raise only 16.7 billion in bond markets and turned to the EU and IMF for another 37.8 billion. To take another EU example, Italy had over 53 billion euros maturing in the month of September 2011, alone (relative to average monthly tax revenue of 57 billion). When Italian yields started to spike in the summer of 2011, whether this debt could be rolled over (with or without assistance) became a central concern. Italy did not default and avoided a direct bailout (although it indirectly benefited from a host of European Central Bank activities), and ended 2011 with more debt outstanding than at the start of the year. This outcome of successfully navigating a crisis but at the cost of additional debt will be an equilibrium outcome in our model. The key factor in all these episodes is high-frequency uncertainty about events between today's auction and the next bond payment.

The paper initially establishes these insights in an analytical model. We then explore how

\footnotetext{
${ }^{2}$ Right after the first devaluation on December 20th, the government lost $\$ 4.5$ billion in reserves in a single day defending the peso. This led the government to announce that it was abandoning targeting the exchange rate on December 22. At the December 27 tesobono auction only $\$ 28$ million of the $\$ 416$ million in bonds on offer were sold. See Whitt Jr. (1996) for a description and detailed analysis of events.
} 
the presence of intra-period risk (both on and off the equilibrium path) changes the model's quantitative predictions. To do this in a transparent way, we start with a standard oneperiod quantitative model in the spirit of Eaton and Gersovitz (1981), Aguiar and Gopinath (2006), and Arellano (2008) and focus on Mexico. In the standard model, absent a highly non-linear cost of default, which essentially forgives default in low endowment states, the government rarely defaults and spread volatility is very low. We show that allowing creditors to coordinate on the "desperate deal" intermediate price schedule makes it possible to match the observed volatility of Mexican spreads with linear default costs. The equilibrium jump in spread volatility is driven entirely by the government over borrowing in response to the depressed price schedule. ${ }^{3}$ In contrast, in the model without belief shocks or with the canonical Cole-Kehoe rollover crises there is no over borrowing and, consequently, spread volatility is much lower. We then proceed to the long-term debt case and show that the key insight regarding over borrowing and spread volatility continues to apply. In the appendix, we confirm that these quantitative findings carry over to the case of Italy. We also confirm that our findings for Mexico are robust to assuming that the government keeps only half of the auction revenue in default as opposed to all of it.

\section{Model}

\subsection{Environment}

We consider a single-good, discrete-time environment. There is a small open economy that (initially) has access to international capital markets. We assume that the economy's aggregate consumption and saving decisions are made by a sovereign government. The economy receives a stochastic endowment $Y_{t} \in \mathbb{Y} \equiv[\underline{Y}, \bar{Y}]$, with $0<\underline{Y}<\bar{Y}<\infty$. For this section, we assume $Y_{t}$ is i.i.d. over time. The government's preferences over the sequence of aggregate consumption $\left\{C_{t}\right\}_{t=0}^{\infty}$ is given by $\mathbb{E}_{0} \sum_{t=0}^{\infty} \beta^{t} u\left(C_{t}\right)$, where $\beta \in(0,1)$ and $u: \mathbb{R}^{+} \rightarrow \mathbb{R}$ is continuously differentiable, strictly increasing, and strictly concave.

The rest of the world is populated by risk-neutral lenders who discount at the rate $R^{-1}=\left(1+r^{*}\right)^{-1}$. The government has access to a one-period, non-contingent discount bond on which it can default. Let $B$ denote the outstanding stock of bonds at the start of a period; note that $B>0$ indicates the government is a net debtor, and $B<0$ a net creditor. To rule out Ponzi schemes, we place an upper bound on debt, $\bar{B}>0$; that is, $B \in(-\infty, \bar{B}]$. We assume $\bar{B}$ is strictly greater than the natural borrowing limit, and hence never binds in

\footnotetext{
${ }^{3}$ The "sudden stop" response to the crisis occurs at lower debt levels, while the typical best response near the ergodic mean level of debt is to issue additional debt during a crisis.
} 
equilibrium.

\subsection{Timing}

The timing of events within a period is depicted in Figure 1. The government enters with a debt payment due in the current period of $B$. At the start of the period, the endowment $Y$ is realized. A sunspot that coordinates creditor beliefs, $\rho$, is also realized. The sunspot will be discussed in detail in Section 2.7. After observing the states $s \equiv(Y, \rho, B)$, and given an equilibrium price schedule $q\left(s, B^{\prime}\right)$, the government decides how much debt to issue (or assets to buy), denoted by $B^{\prime}$.

After the auction, the government decides whether or not to repay the outstanding debt $B$. The fact that the default/repayment decision takes place after the auction is crucial to the analysis. This timing follows Cole and Kehoe (2000) and differs from Eaton and Gersovitz (1981) and the existing quantitative literature. However, relative to Cole-Kehoe, we enrich the setting by allowing for additional information to arrive between the auction and repayment. The original Cole-Kehoe analysis had perfect foresight within a period.

Let $V^{R}\left(s, B^{\prime}\right)$ denote the value of the government if it repays $B$ after issuing $B^{\prime}$ in state $s$. The value functions will be defined below. If the government defaults, it receives $V^{D}\left(s, B^{\prime}\right)+\sigma \epsilon$, where $\sigma>0$ is a parameter and $\epsilon$ is a shock that affects the returns to default. This shock becomes known only after the auction, but prior to the default decision. ${ }^{4}$ A natural interpretation of $\epsilon$ is the high frequency realization of political payoffs to default that are orthogonal to output and the quantity of debt due. We show below that we can recast the shock as a bailout of random size from a third party like the IMF or the ECB.

We assume $\epsilon$ is distributed i.i.d. over time with cdf $F$ and a continuous density on support $[0,1] .{ }^{5}$ We assume $F^{\prime}(\epsilon) \geq \alpha>0$ on $[0,1]$ for some strictly positive constant $\alpha$. We shall show that as $\sigma \rightarrow 0$, and the uncertainty over payoffs becomes negligible, we do not necessarily converge to the perfect-foresight equilibria of Cole and Kehoe (2000). That is, an arbitrarily small amount of uncertainty about default payoffs opens a door to a richer set of self-fulfilling crises than that studied by Cole and Kehoe (2000).

Much of the novel economics in this paper stems from thinking carefully about the gap in time between the auction of new bonds and repayment of old bonds. Given its importance in the analysis, it is useful to say a few things about the timing assumption. In the EatonGersovitz model, prior to auctioning new bonds the government can commit to repayment

\footnotetext{
${ }^{4}$ There is a long history of such random payoffs to default. See the handbook chapters of Eaton and Fernandez (1995) and Aguiar and Amador (2014) as well as more recent papers by Aguiar et al. (2019) and Chatterjee et al. (2020).

${ }^{5}$ Given the parameter $\sigma$, the (bounded) size of the support of $\epsilon$ can be normalized to one without loss. The location of the support shifts the value of default by a constant.
} 
of maturing bonds as well as to the amount of bonds to be auctioned that period. With one-period bonds, this decouples the current auction from the risk faced by existing bonds. Introducing longer maturity bonds gives rise to dilution risk as well as multiplicity. ${ }^{6}$ In Eaton-Gersovitz, the multiplicity is tied to the inability to commit to future bond issuances, as the one-period bond model has a unique equilibrium (Auclert and Rognlie (2016)). It is instructive to abstract from dilution risk while maintaining the gap between the issuance of new debt and repayment of old. The timing in Figure 1 does exactly that. Our multiplicity exists separate from dilution risk because it is fundamentally "static" in nature: We could have risk-free prices from period $t+1$ onwards, but still have multiple outcomes in period $t$.

Figure 1: Timing Within a Period

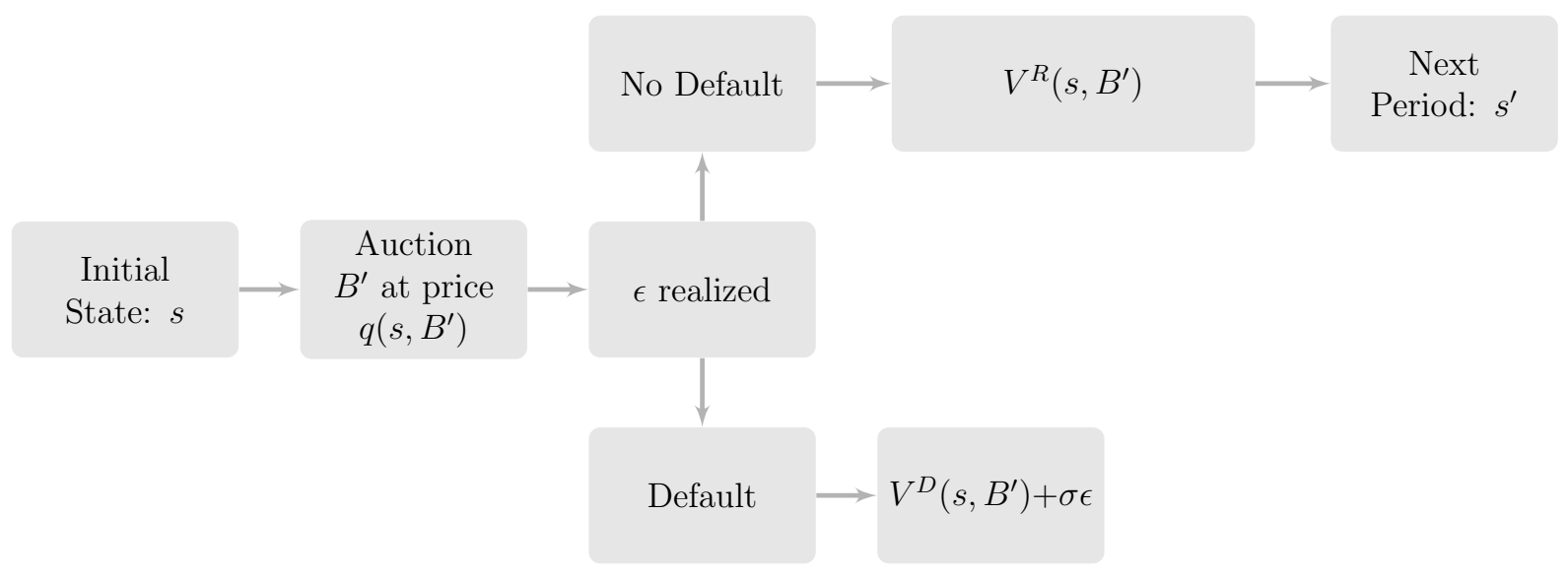

\subsection{The Government's Problem}

We shall consider equilibria such that the equilibrium outcome is a function of $s=(Y, \rho, B)$ and the credit history. If the government has not defaulted in the past, it faces an equilibrium price schedule for new debt $B^{\prime}$ given by $q\left(s, B^{\prime}\right)$. The government takes the schedule as given but recognizes that the price of its debt may vary with $B^{\prime}$.

Let $V(s)$ denote the equilibrium value of the government in good credit standing prior to the period's auction. We can characterize the government's problem recursively by iterating on $V$. In particular, let $V_{0}(s)$ describe the conjectured government's continuation value starting from the next period, and we shall construct the value at the start of today's period, $V_{1}$. The equilibrium $V$ will be the fixed point of this mapping.

Working backwards through the current period, if the government repays, it obtains

\footnotetext{
${ }^{6}$ See Stangebye (2020) and Aguiar and Amador (2020).
} 
value:

$$
V^{R}\left(s, B^{\prime}\right)=u\left(Y+q\left(s, B^{\prime}\right) B^{\prime}-B\right)+\beta \mathbb{E}\left[V_{0}\left(s^{\prime}\right) \mid B^{\prime}\right]
$$

if $Y+q\left(s, B^{\prime}\right) B^{\prime}-B \geq 0$. If $Y+q\left(s, B^{\prime}\right) B^{\prime}-B<0$, then repayment is infeasible. For infeasible allocations, we set the government's value to minus infinity, as default will always dominate this value.

If the government defaults, it consumes its endowment and the revenue from the period's bond auction and then remains in financial autarky thereafter. In this section, we abstract from reentry to financial markets. Letting $\underline{V}^{D} \equiv \mathbb{E} u\left(Y^{\prime}\right) /(1-\beta)$, we define:

$$
V^{D}\left(s, B^{\prime}\right) \equiv u\left(Y+q\left(s, B^{\prime}\right) B^{\prime}\right)+\beta \underline{V}^{D} .
$$

Strategic default implies that the government repays if and only if:

$$
\epsilon \leq \frac{1}{\sigma} \cdot \underbrace{\left[V^{R}\left(s, B^{\prime}\right)-V^{D}\left(s, B^{\prime}\right)\right]}_{\equiv \Delta\left(s, B^{\prime}\right)}
$$

where the expression in brackets defines $\Delta\left(s, B^{\prime}\right)$ as the net benefit of repayment when $\epsilon=0$. Conditional on $\left(s, B^{\prime}\right)$, the equilibrium probability of repayment within the period is therefore $F\left(\sigma^{-1} \Delta\left(s, B^{\prime}\right)\right)$. $^{7}$

At the time of auction, the government's problem is to choose $B^{\prime} \leq \bar{B}$ to maximize the expected end-of-period value: $V_{1}(s)=\max _{B^{\prime}} \mathbb{E}\left\{\max \left\langle V^{R}\left(s, B^{\prime}\right), V^{D}\left(s, B^{\prime}\right)+\sigma \epsilon\right\rangle\right\}$, where expectation is over the realization of $\epsilon$. With some rearranging (see appendix), we obtain:

$$
V_{1}(s)=\max _{B^{\prime} \leq \bar{B}}\left\{V^{D}\left(s, B^{\prime}\right)+\sigma-\sigma \int_{\sigma^{-1} \Delta\left(s, B^{\prime}\right)}^{1} F(\epsilon) d \epsilon\right\} .
$$

The right-hand side of (4) depends on the equilibrium value function through $\Delta$. Hence, equation (4) implicitly defines an operator $T$, conditional on $q$, that maps $V_{0}$ to $V_{1}=T V_{0}$. Given a price schedule, the solution to the government's problem $V$ is the fixed point of this operator. It will be clear in what follows that the economics behind the self-fulfilling crises we study do not rely on the fact that the continuation value function is the same as the current value function. That is, the insights carry over to a finite horizon model or other

\footnotetext{
${ }^{7}$ Note that if the government has assets $(B<0)$, we have $\Delta>0$. Nevertheless, from (3), if $\epsilon$ is large enough, the government may prefer to walk away from its asset position. In that event, we assume that the counter-party continues to pay out on the assets (in accordance with the risk-free interest rate paid on assets), but the payments are lost to the government due to an un-modelled deadweight loss. As $\sigma \rightarrow 0$, this event never arises in equilibrium.
} 
non-stationary environments.

Random Bailout: Before proceeding, we highlight that another interpretation of the intra-period risk is uncertainty over the size of a potential bailout from a third party, like the IMF or the ECB. Suppose at the time of settlement, the government seeks assistance from the third party. The third party agrees to transfer $\sigma \varepsilon$ conditional on repayment, with $\varepsilon$ drawn from a distribution with support $[0,1]$. The value of repayment conditional on the draw of $\varepsilon$ is:

$$
u\left(Y-B+q\left(s, B^{\prime}\right) B^{\prime}+\sigma \varepsilon\right)+\beta \mathbb{E}\left[V\left(s^{\prime}\right) \mid B^{\prime}\right] .
$$

The value of default is $V^{D}\left(s, B^{\prime}\right)$ given in equation (2). The government repays as long as:

$$
u\left(y-B+q\left(s, B^{\prime}\right) B^{\prime}-\sigma \varepsilon\right) \geq u\left(Y+q\left(s, B^{\prime}\right) B^{\prime}\right)+\beta \underline{V}-\beta \mathbb{E}\left[V\left(s^{\prime}\right) \mid B^{\prime}\right] .
$$

Rearranging, we have repayment if and only if:

$$
\varepsilon \geq \frac{1}{\sigma} \cdot \underbrace{u^{-1}\left[u\left(Y+q\left(s, B^{\prime}\right) B^{\prime}\right)+\beta \underline{V}-\beta \mathbb{E}\left[V\left(s^{\prime}\right) \mid B^{\prime}\right]\right]-Y+B-q\left(s, B^{\prime}\right) B^{\prime}}_{\equiv \hat{\Delta}\left(s, B^{\prime}\right)}
$$

where $u^{-1}$ is the inverse of the utility function. This expression takes the same form (with a reversed inequality) as the benchmark model's expression (3). Hence, we can recast the intra-period uncertainty as ambiguity about whether (and by how much) the government will be assisted in repaying maturing debt.

\subsection{The Lenders' Problem}

Given the small open economy and risk-neutral lenders, prices must satisfy a break-even condition. Specifically, let $\Delta\left(s, B^{\prime}\right)$ be part of an equilibrium, and let $\mathcal{B}(s)$ denote the government's equilibrium policy function for debt issuance. The price schedule $q: S \times$ $(-\infty, \bar{B}] \rightarrow\left[0, R^{-1}\right]$ must equate the expected return on sovereign debt to the risk-free rate. Assets $\left(B^{\prime} \leq 0\right)$ always carry the risk-free price $R^{-1}$. For $B^{\prime} \in(0, \bar{B}]$, the break-even condition is:

$$
q\left(s, B^{\prime}\right)=R^{-1} \times F\left(\sigma^{-1} \Delta\left(s, B^{\prime}\right)\right) \times \mathbb{E}\left[F\left(\sigma^{-1} \Delta\left(s^{\prime}, \mathcal{B}\left(s^{\prime}\right)\right)\right) \mid B^{\prime}\right] \text { if } B^{\prime} \in(0, \bar{B}] .
$$

Our timing implies that bondholders are vulnerable to two default decisions, one in the current period immediately after auction and one after next period's auction. Since next period's default probability depends on next period's debt choice, the pricing also depends 
on the government's borrowing policy function $\mathcal{B}$.

The definition of equilibrium is standard:

Definition 1. An equilibrium consists of a price schedule q, a government value function $V$ with associated policy $\mathcal{B}$ such that: (i) $V$ and $\mathcal{B}$ solve the government's problem (4) given $q$; and (ii) $q$ satisfies the break-even condition (5) given $\mathcal{B}$.

\subsection{Static Multiplicity}

It is useful to describe the multiplicity inherent in the environment by focusing on a single period, holding future (equilibrium) behavior constant. In particular, let $\{q, \mathcal{B}, V\}$ denote a "continuation equilibrium" that governs behavior from next period onwards. The multiplicity in the model is inherently "static" in the sense that we can hold continuation play fixed while supporting alternative prices and policies in the current period.

Fix an initial state, $(Y, B)$, and a choice of debt to be auctioned, $B^{\prime} \in(0, \bar{B}]$. Given fixed $\left(Y, B, B^{\prime}\right)$, the only thing that varies are beliefs about government behavior at settlement. In particular, from (5) the key determinant of alternative equilibrium prices is the probability of default at settlement, $F\left(\sigma^{-1} \Delta\left(s, B^{\prime}\right)\right)$. Beliefs are captured in our notation by the state variable $\rho$. For now, we suppress this state variable (for the current period) and construct alternative candidate outcomes for a given $\left(Y, B, B^{\prime}\right)$ and a fixed continuation equilibrium (which implicitly includes a distribution over next period's beliefs). After establishing the type of equilibrium behavior that can be supported, we map $\rho$ to particular outcomes.

Given a continuation equilibrium, we can define the reference price that satisfies (5) assuming the government will repay maturing bonds $B$ with probability one at settlement. This replicates (for the current period) the Eaton-Gersovitz assumption that the government can commit to repayment of maturing bonds prior to the current period's auction. Hence, we use the subscript $E G$ to identify this reference price, which is defined by:

$$
q_{E G}\left(B^{\prime}\right) \equiv R^{-1} \mathbb{E}\left[F\left(\Delta\left(s^{\prime}, \mathcal{B}\left(s^{\prime}\right)\right)\right) \mid B^{\prime}\right] .
$$

The difference between (6) and (5) is we have set $F\left(\sigma^{-1} \Delta\left(s, B^{\prime}\right)\right)=1$, reflecting the zero probability of default in the current period. This makes $q_{E G}$ an upper bound on the equilibrium price schedule conditional on the continuation equilibrium. Given the i.i.d. assumptions and the fact that $q_{E G}$ is determined by next period's default decisions, $q_{E G}$ is a function only of $B^{\prime}$. We are holding $B^{\prime}$ fixed for the present discussion, and hence for the remainder of the sub-section we subsume the argument of $q_{E G}$ when convenient.

Fixing $\left(Y, B, B^{\prime}\right)$, let $\tilde{q} \in\left[0, q_{E G}\right]$ denote a candidate equilibrium price for the newly auctioned bonds. From (5), $\tilde{q}$ is $q_{E G}$ multiplied by the probability of default in the current 
Figure 2: Within-Period Price Determination

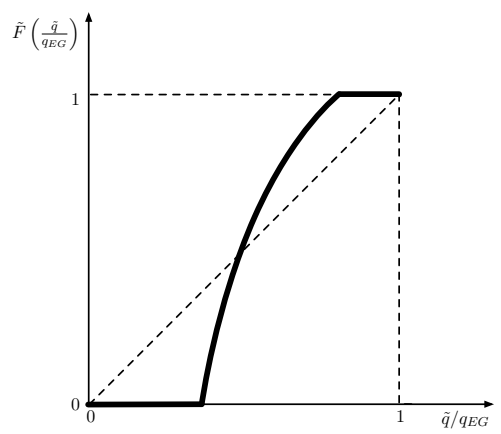

(a)

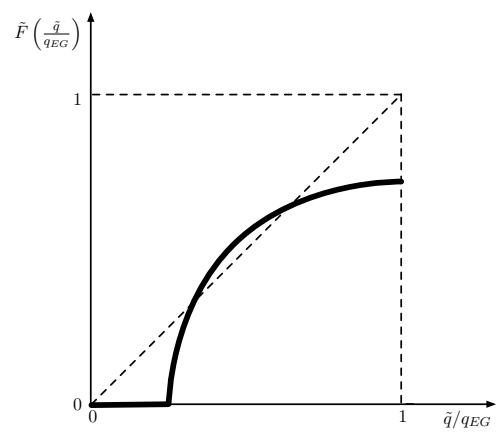

(b)

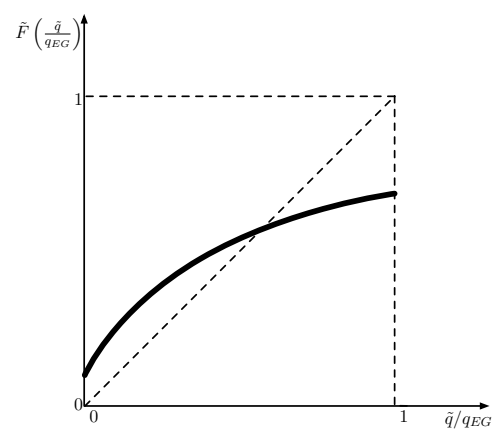

(c)

Depiction of equilibrium condition equation (8). Panel (a) depicts the benchmark case of zero, $q_{E G}$, and an interior price all being possible equilibria; Panel (b) the case of zero and two interior prices; and Panel (c) for a sole price, which is interior.

period. Given $\tilde{q}$, let

$$
\tilde{\Delta} \equiv u\left(Y-B+\tilde{q} B^{\prime}\right)-u\left(Y+\tilde{q} B^{\prime}\right)+\beta \mathbb{E}\left[V\left(s^{\prime}\right) \mid B^{\prime}\right]-\beta \underline{V}^{D} .
$$

The probability of repayment this period is the probability that $\tilde{\Delta} \geq \sigma \epsilon$. The equilibrium condition (5) can be written as:

$$
\frac{\tilde{q}}{q_{E G}}=F\left(\sigma^{-1} \tilde{\Delta}\right) \equiv \tilde{F}\left(\tilde{q} / q_{E G}\right)
$$

where the last term uses the definition of $\tilde{\Delta}$ in $(7)$ and the fact that $q_{E G}$ is held constant for this exercise to define the probability of repayment as a function of the ratio $\tilde{q} / q_{E G}$. Our candidate $\tilde{q}$ satisfies the conditions for equilibrium if and only if it satisfies equation (8). Equation (8) maps $[0,1]$ into itself. The static multiplicity then arises from the fact that there may be multiple valid solutions to (8).

We now discuss three possible classes of equilibrium prices. To guide the discussion, Figure 2 is a heuristic diagram depicting the fixed point problem of equation (8). In each panel of the figure, we let $\tilde{q} / q_{E G}$ vary between zero and one on the horizontal axis and plot $\tilde{F}(\cdot)$. From (8), valid equilibrium prices consist of points where this function intersects the 45-degree line. $\tilde{F}$ inherits the continuity of $u$, and the concavity of $u$ implies that $\tilde{F}$ is weakly increasing when the government enters the period with debt, and strictly increasing for $\tilde{q} \in\left[0, q_{E G}\right]$ such that $\sigma^{-1} \tilde{\Delta} \in(0,1) .{ }^{8}$ This is the case depicted in Figure 2. For $B \leq 0$, the government enters the period with assets; the proof of Proposition 2 establishes that the

\footnotetext{
${ }^{8}$ The proof of Proposition 3 establishes the concavity of $\tilde{F}$ on $(0,1)$ for a broad class of distributions $F$ and utility functions.
} 
government will never default in this case for small $\sigma$. We initially focus on panel (a), and then discuss the remaining two panels at the end of this section.

The "Eaton-Gersovitz" Price: One possibility is that $\tilde{q}=q_{E G}$ is an equilibrium; that is, there is zero intra-period risk of default. To establish when this is a valid equilibrium price, define the value of repayment at the Eaton-Gersovitz price by

$$
V_{E G}^{R}\left(Y, B, B^{\prime}\right) \equiv u\left(Y+q_{E G}\left(B^{\prime}\right) B^{\prime}-B\right)+\beta \mathbb{E}\left[V\left(s^{\prime}\right) \mid B^{\prime}\right]
$$

Similarly, define the associated default value at price $q_{E G}$ by $V_{E G}^{D}\left(Y, B^{\prime}\right)+\sigma \epsilon$, where:

$$
V_{E G}^{D}\left(Y, B^{\prime}\right) \equiv u\left(Y+q_{E G}\left(B^{\prime}\right) B^{\prime}\right)+\beta \underline{V}^{D}
$$

The Eaton-Gersovitz price is a valid equilibrium price for $\left(Y, B, B^{\prime}\right)$ if and only if

$$
V_{E G}^{R}\left(Y, B, B^{\prime}\right)-V_{E G}^{D}\left(Y, B^{\prime}\right) \geq \sigma
$$

This implies that $\tilde{\Delta} \geq \sigma$ for $\tilde{\Delta}$ defined in equation (7) evaluated at $\tilde{q}=q_{E G}$. In panel (a) of Figure 2, $q_{E G}$ is a valid equilibrium as $\tilde{F}(1)=1$. In this scenario, by facing a high price at auction, the government's burden of repayment (both in terms of consumption today and debt going forward) is relatively low and the threat of default at settlement is therefore zero.

The Cole-Kehoe "Failed-Auction" Price: A second possibility is that $\tilde{q}=0$ is an equilibrium. This is reminiscent of the canonical Cole-Kehoe rollover crisis, in which $B^{\prime}$ raises zero at auction and the government defaults at settlement with probability one. Specifically, define $^{9}$

$$
V_{C K}^{R}\left(Y, B, B^{\prime}\right) \equiv u(Y-B)+\beta \mathbb{E}\left[V\left(s^{\prime}\right) \mid B^{\prime}\right]
$$

Note that as $\tilde{q}=0$, the value of repayment depends on $B^{\prime}$ only through the continuation value (as $B^{\prime} \in s^{\prime}$ ). For $\tilde{q}=0$ to be an equilibrium price, (8) requires:

$$
V_{C K}^{R}\left(Y, B, B^{\prime}\right)-u(Y)-\beta \underline{V}^{D} \leq 0 .
$$

In panel (a) of Figure 2, zero is a valid equilibrium as $\tilde{F}(0)=0$. In this scenario, because of failure to raise any revenue at auction, the burden of repayment of maturing bonds is relatively high, leading to default with probability one at settlement, rationalizing the zero

\footnotetext{
${ }^{9}$ The government always purchases assets at risk-free prices, so $V_{C K}^{R}\left(., ., B^{\prime}\right)=V_{E G}^{R}\left(., ., B^{\prime}\right)$ for $B^{\prime} \leq 0$.
} 
price.

Interior Prices: The third possibility is that there exists $\tilde{\epsilon} \in[0,1]$ at which the government is indifferent to repayment and default. In particular, consider a $\tilde{\epsilon}$ such that:

$$
\sigma \tilde{\epsilon}=u\left(Y-B+F(\tilde{\epsilon}) q_{E G} B^{\prime}\right)-u\left(Y+F(\tilde{\epsilon}) q_{E G} B^{\prime}\right)+\beta \mathbb{E}\left[V\left(s^{\prime}\right) \mid B^{\prime}\right]-\beta \underline{V}^{D} .
$$

In this case, the auction price is $\tilde{q}=F(\tilde{\epsilon}) q_{E G}$, and whether the government repays or defaults after the auction depends on the realization of $\epsilon \gtrless \tilde{\epsilon}$. The government strictly prefers to repay if $\epsilon<\tilde{\epsilon}$ and default if $\epsilon>\tilde{\epsilon}$, and $\epsilon=\tilde{\epsilon}$ is the measure-zero point of indifference. We refer to this case as an interior price:

Definition 2. For a given $\left(s, B^{\prime}\right)$, an equilibrium price $q\left(s, B^{\prime}\right)=F(\tilde{\epsilon}) q_{E G}\left(B^{\prime}\right)$ is interior if $\tilde{\epsilon} \in[0,1]$ satisfies (13). The price is strictly interior if $\tilde{\epsilon} \in(0,1)$.

At strictly interior prices, the government faces strictly positive but depressed (relative to $\left.q_{E G}\right)$ prices. At auction, the bonds are priced as if they are a standard "Eaton-Gersovitz" bond combined with a lottery on the realization of $\epsilon \gtrless \tilde{\epsilon}$.

Such an interior price is a generic feature of the static multiplicity inherent in the model. By this, we mean that if there are multiple prices that can be supported in equilibrium, then an interior price can also be supported. In particular, at a given $\left(Y, B, B^{\prime}\right)$, if the government prefers to repay when facing $q_{E G}$ and to default when the price is zero, then there exists an interior equilibrium price:

Proposition 1. For a fixed $\left(Y, B, B^{\prime}\right)$, suppose that (i) $V_{E G}^{R}\left(Y, B, B^{\prime}\right)-V_{E G}^{D}\left(Y, B^{\prime}\right) \geq \sigma$, and (ii) $V_{C K}^{R}\left(Y, B, B^{\prime}\right)-V_{C K}^{D}(Y) \leq 0$, then there exists an interior equilibrium price. If the inequalities in (i) and (ii) are strict, then there exists a strictly interior equilibrium price.

In panel (a) of Figure 2, as $\tilde{F}(0)=0$ and $\tilde{F}(1)=1$, there must be a $x \in[0,1]$ such that $\tilde{F}(x)=x$. As depicted, $x \in(0,1)$, and hence constitutes a third distinct equilibrium price. There are also the knife-edge cases with only two valid prices, with either $\tilde{\epsilon}=0$ or $\tilde{\epsilon}=1$ satisfying equation (13).

Note that Proposition 1 does not require any restrictions on the distribution of $\epsilon$ other than compact support and a continuous $c d f$. The fact that Proposition 1 holds regardless of the size of $\sigma$ is noteworthy given the empirical motivation. The time between an auction of new bonds and repayment of old may be quite short in practice. Even if the magnitude of high-frequency risk is arbitrarily small, the proposition establishes that the mere presence of such risks remains relevant for equilibrium price determination. One contribution of this paper is to incorporate such uncertainty into a model of self-fulfilling debt crises. 
In this spirit, we sharpen the characterization of multiplicity using two approaches. One is place no restrictions on $F$ and let $\sigma \rightarrow 0$, thereby studying the impact of arbitrarily small intra-period risk. An alternative view is that asset prices show significant volatility at high frequencies, particularly during crises, and therefore high-frequency risk may indeed be significant. Hence, the second approach is to place some structure on $F$ without restricting $\sigma$ to be arbitrarily small. We tackle each in turn.

Proposition 1 does not rule out that there may be more than one interior fixed point to equation (8). Moreover, the proposition provides sufficient conditions for an interior equilibrium, but it is silent on whether an interior price can be supported in other scenarios. The next proposition states that for small $\sigma$ there is at most one interior price, and generically there exists either one equilibrium price or three:

Proposition 2. For a given $\left(Y, B, B^{\prime}\right)$, there exists a $K>0$ such that if $\sigma<K$, then there are only three possible equilibrium price configurations:

(i) Zero is the only equilibrium price;

(ii) $q_{E G}$ is the only equilibrium price; or

(iii) $\left\{0, q_{E G}, F(\tilde{\epsilon}) q_{E G}\right\}$ can all be supported as equilibrium prices, where $\tilde{\epsilon} \in[0,1]$ is the unique solution to equation (13).

Proposition 1 gives sufficient conditions for an interior price. Proposition 2 states they are also necessary for small $\sigma .^{10}$

The preceding propositions characterized the static multiplicity for arbitrarily small intraperiod risk. As noted above, an alternative view is that there is a non-negligible chance that significant information arrives between an auction and the next payment of debt. We now explore the scenario in which $\sigma>>0$. In particular, we show that there is a large class of utility functions and densities $F$ for which there exist at most three possible equilibrium prices:

Proposition 3. Suppose $Y>B>0$ and $q_{E G}\left(B^{\prime}\right) B^{\prime}>0$. If $u^{\prime \prime}(c)$ is strictly increasing in $c \geq 0$ and $F^{\prime}(\epsilon)$ is weakly decreasing in $\epsilon \in[0,1]$, then there are at most three $\tilde{q}$ that satisfy (8), with at most two interior. If $\tilde{q}=0$ is not an equilibrium, then there is at most one equilibrium price that satisfies (8).

\footnotetext{
${ }^{10}$ One can consider the limiting case of $\sigma=0$ as a price that makes the government indifferent to default and repayment, which is supported as an equilibrium by the government randomizing over the default decision. We formalize this notion in Appendix B.
} 
Panels (b) and (c) in Figure 2 consider the scenario discussed in Proposition 3. In particular, in Panel (b), $B^{\prime}$ is such that there are three possible equilibrium prices, but $q_{E G}\left(B^{\prime}\right)$ is not among them. Rather, the highest possible price is associated with some risk of immediate default. A second interior price is associated with a greater chance of default within the period. Zero remains an equilibrium as well, which is associated with probability-one immediate default.

In Panel (c), $B^{\prime}$ is such that zero is no longer an equilibrium price. The only equilibrium price is an interior price. Again, this arises when $\sigma$ is large enough that there is always a substantial risk (but not certainty) of default at settlement. In particular, such an outcome requires that the government strictly prefers to repay when $\epsilon=0$ when facing a zero price and strictly prefers to default when $\epsilon=1$ when facing the Eaton-Gersovitz price. From Proposition 2, this requires a $\sigma$ bounded away from zero.

Not depicted in Figure 2 are the straightforward cases in which $\tilde{q}=0$ or $\tilde{q}=q_{E G}\left(B^{\prime}\right)$ are the unique equilibrium prices. For the former, the $\tilde{F}$ curve is below the 45-degree line for the entire domain. That is, even at the best possible price, the government strictly prefers to default. For the latter, even at a zero price the government strictly prefers to repay, implying the $\tilde{F}$ curve lies above the 45-degree line over the entire domain $[0,1]$.

\subsection{Regions of Multiplicity}

We now discuss how the possibility of multiplicity varies with the states $(Y, B)$ and choice $B^{\prime}$. We continue focusing on static multiplicity by fixing a continuation value $V$ and associated policy $\mathcal{B}$, and then analyzing alternative equilibrium behavior in the current period. For the formal analysis, there is no need to place additional restrictions on future equilibrium behavior (beyond those in the equilibrium definition); for clarity, the heuristic diagrams used in the exposition will assume that $\mathbb{E}\left[V\left(s^{\prime}\right) \mid B^{\prime}\right]$ and $q_{E G}\left(B^{\prime}\right)$ are continuous and weakly decreasing in $B^{\prime}{ }^{11}$

To get a better sense of when and how multiplicity arises in our environment, we use Figure 3. Both panels have the same set of curves, but are evaluated at different points in the state space $(Y, B)$. The solid hump-shaped line depicts $V_{E G}^{R}\left(Y, B, B^{\prime}\right)$ as we vary $B^{\prime}$ and fix $(Y, B)$. The non-monotonicity comes from the fact that as we increase $B^{\prime}$, current consumption increases (subject to being on the upward part of the debt Laffer curve; that is, $\left.d\left[q\left(B^{\prime}\right) B^{\prime}\right] / d B^{\prime}>0\right)$. However, an increase in $B^{\prime}$ weakly reduces the continuation value.

\footnotetext{
${ }^{11}$ As a technical aside, the continuity of $V(s)$ in $B$ is relatively straightforward to prove in the one-perioddebt Eaton-Gersovitz model (see, for example, Auclert and Rognlie (2016) and Aguiar and Amador (2019)). The complication introduced by the Cole-Kehoe timing is that the price schedule $q$ depends on both $B$ and $B^{\prime}$, and, depending on the equilibrium selection assumptions, $q$ is potentially discontinuous in $B$ and hence the budget set can shift discontinuously in the state variable $B$.
} 
Figure 3: Value Functions

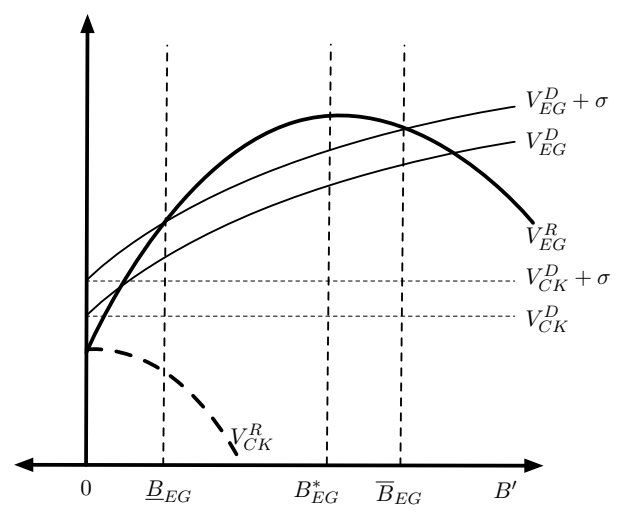

(a) Canonical "Crisis Zone"

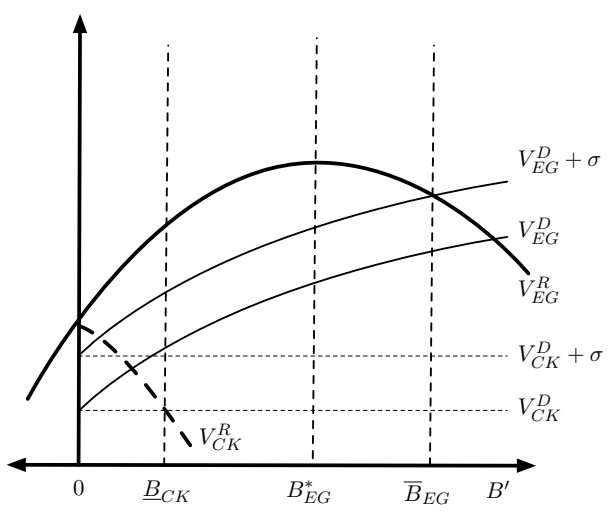

(b) Extended "Crisis Zone"

Depiction of $V_{i}^{R}$ and $V_{i}^{D}, i=E G, C K$, as functions of $B^{\prime}$. Panel (a) depicts the canonical Crisis Zone in which 0 is a valid price for all $B^{\prime}>0$, and $q_{E G}$ is valid on the domain $\left[\underline{B}_{E G}, \bar{B}_{E G}\right]$. $B_{E G}^{*}$ depicts the optimum conditional on facing the $q_{E G}$ schedule. Panel (b) is the same figure, but drawn for a higher initial net endowment $Y-B$. Zero is valid only for $B^{\prime} \geq \underline{B}_{C K}$ and $q_{E G}$ for $\left[0, \bar{B}_{E G}\right]$.

Once $B^{\prime}$ reaches the downward sloping part of the Laffer curve, $V_{E G}^{R}$ unambiguously weakly declines in $B^{\prime}$. The peak of $V_{E G}^{R}$ indicates the optimal issuance policy given $q_{E G}$, which is denoted $B_{E G}^{*}$ in the figure. ${ }^{12}$

We also include the value of repayment in the event of a failed auction, $V_{C K}^{R}\left(Y, B, B^{\prime}\right)$ defined in equation (12) (i.e., the value if $B^{\prime}>0$ were to be issued at a zero price). $V_{C K}^{R}$ is depicted in Figure 3 by the downward sloping dashed line. For $B^{\prime}>0, V_{C K}^{R}(Y, B, \cdot)$ depends on $B^{\prime}$ only through continuation value, which we depict as decreasing in debt carried forward. As no revenue is raised at auction, $V_{C K}^{R}$ is less than $V_{E G}^{R}$ (on the domain such that $\left.q_{E G}\left(B^{\prime}\right) B^{\prime}>0\right)$. For $B^{\prime}<0, V_{C K}^{R}$ tracks $V_{E G}^{R}$, as assets are always purchased at risk-free prices.

In the figure, we also include the upper and lower limits for the value of default given $Y$ and the price schedule $q_{E G}$, which are the lines labeled $V_{E G}^{D}$ and $V_{E G}^{D}+\sigma$ in the figure. The default values are increasing in $B^{\prime}$ as long as auction revenue is increasing; that is, as long as $B^{\prime}$ is on the upward sloping portion of the debt Laffer curve.

The horizontal dotted lines labeled $V_{C K}^{D}$ and $V_{C K}^{D}+\sigma$ give the range of default values under a zero price. These are invariant to the choice of $B^{\prime}$, as the price of issued bonds is always zero. The $V_{E G}^{D}$ lines equal their $V_{C K}^{D}$ counterparts when $B^{\prime}=0$, as auction revenue is zero regardless of price.

\footnotetext{
${ }^{12}$ We cannot state analytically that the function is continuous and single peaked. In our quantitative explorations, $V_{E G}^{R}$ typically turns out to be single peaked, with a few exceptions such as that discussed in footnote 28 .
} 
In Panel (a) we depict the canonical "Crisis Zone" studied by Cole-Kehoe. Specifically, $V_{C K}^{R}$ is less than $V_{C K}^{D}$ for all $B^{\prime} \geq 0$. That is, if the government cannot raise a positive amount at auction, it strictly prefers to default regardless of the realization of $\epsilon$. Thus, zero is an equilibrium price for all $B^{\prime}>0$.

On the other hand, if the government faced the $q_{E G}$ schedule, it would issue $B^{\prime}=B_{E G}^{*}$ and would repay at settlement with probability one. This is because $V_{E G}^{R}\left(Y, B, B_{E G}^{*}\right)>$ $V_{E G}^{D}\left(Y, B_{E G}^{*}\right)+\sigma$. Hence, both default and repayment can be supported in equilibrium.

Due to the lack of commitment to repayment after the auction, the Eaton-Gersovitz price schedule may be valid on only a subset of the debt-issuance domain even under the "best" equilibrium beliefs. Specifically, $q_{E G}\left(B^{\prime}\right)$ is a valid equilibrium price schedule only if $V_{E G}^{R}\left(Y, B, B^{\prime}\right) \geq V_{E G}^{D}\left(Y, B^{\prime}\right)+\sigma$. Define: $\mathbb{B}_{E G}(Y, B) \equiv\left\{B^{\prime} \in[0, \bar{B}] \mid V_{E G}^{R}\left(Y, B, B^{\prime}\right) \geq\right.$ $\left.V_{E G}^{D}\left(Y, B^{\prime}\right)+\sigma\right\}$. On this domain, the Eaton-Gersovitz price is consistent with zero probability of default at settlement. As we are fixing $(Y, B)$ in this discussion, we shall drop the arguments of $\mathbb{B}_{E G}$ when convenient. If $V_{E G}^{R}$ and $V_{E G}^{D}$ are continuous in $B^{\prime}, \mathbb{B}_{E G}$ is a closed set, although it may be the empty set if default dominates repayment at all levels of debt issuances. When $V_{E G}^{R}(Y, B,)-.V_{E G}^{D}(Y,$.$) is single peaked and continuous, as it is$ depicted in Figure 3 , we have $\mathbb{B}_{E G}=\left[\underline{B}_{E G}, \bar{B}_{E G}\right]$, where $\underline{B}_{E G}(Y, B) \equiv \min \mathbb{B}_{E G}(Y, B)$ and $\bar{B}_{E G}(Y, B) \equiv \max \mathbb{B}_{E G}(Y, B)$. Outside of $\mathbb{B}_{E G}$, there is a possibility that the government defaults even if it had auctioned debt at the Eaton-Gersovitz price, eliminating the EatonGersovitz price schedule as a potential equilibrium outcome for such $B^{\prime}$.

By Proposition 1, given that $q=0$ is an equilibrium price for all $B^{\prime}>0$ in panel (a), an interior price can be supported in equilibrium for $B^{\prime} \in \mathbb{B}_{E G}$. Specifically, the equilibria map to the example in Panel (a) of Figure 2. We do not depict the value when facing this third price schedule, although by construction it lies between $V_{C K}^{D}$ and $V_{E G}^{D}+\sigma$.

Collecting results, in the scenario depicted in Panel (a) of Figure 3, there are three possible equilibrium price schedules (and combinations thereof): A zero price for all $B^{\prime}>0$, as well as both the Eaton-Gersovitz price and the interior price for $B^{\prime} \in \mathbb{B}_{E G}$.

Following Cole and Kehoe (2000), the standard construction of a rollover crisis equilibrium is to allow a run to occur only if a zero price is valid for all $B^{\prime}>0$. That is, the government is unable to auction any amount of debt. This is the case depicted in panel (a). However, this is an overly narrow view of failed auctions. To explore this, we introduce and discuss panel (b).

Panel (b) is nearly identical to Panel (a); the lone difference is that the intercept of $V_{C K}^{R}$ is greater than $V_{C K}^{D}$. The difference between panels (a) and (b) reflects different initial states $(Y, B)$, such that $V_{E G}^{R}$ in panel (b) is shifted up relative to the default payoffs. Hence, even at a zero price for new bond issuances, the government strictly prefers to repay maturing bonds 
at $\epsilon=0$. This rules out zero as an equilibrium price in the neighborhood of $B^{\prime}=0$. Define $\mathbb{B}_{C K}(Y, B) \equiv\left\{B^{\prime} \in[0, \bar{B}] \mid V_{C K}^{R}\left(Y, B, B^{\prime}\right) \leq V_{C K}^{D}(Y)\right\}$. If $B^{\prime} \in \mathbb{B}_{C K}$, then a zero price is supportable in equilibrium. The following states that $\mathbb{B}_{C K}$ is non-empty if $B$ is high enough or $Y$ is low enough:

Proposition 4. A necessary and sufficient condition for $\mathbb{B}_{C K}(Y, B) \neq \emptyset$ is

$$
u(Y-B)-u(Y)+\beta \sigma \mathbb{E} \epsilon \leq 0
$$

As $\beta \sigma \mathbb{E} \epsilon>0$, the proposition says that a zero price can be supported for some $B^{\prime} \in[0, \bar{B}]$ if $B$ is high enough (and strictly positive) and $Y$ is low enough (as $u^{\prime}(Y-B)>u^{\prime}(Y)$ when $B>0)$.

For a given $(Y, B)$ such that (14) holds, let $\underline{B}_{C K} \equiv \inf \mathbb{B}_{C K}(Y, B)$. When $\mathbb{E}\left[V\left(s^{\prime}\right) \mid B^{\prime}\right]$ is continuous and weakly decreasing in $B^{\prime}$, as depicted in Figure $3, \mathbb{B}_{C K}=\left[\underline{B}_{C K}, \bar{B}\right]$. In Figure 3 Panel (b), a zero price is not an equilibrium for $B^{\prime}<\underline{B}_{C K}$, but a failed auction is possible if the government were to auction $B^{\prime} \geq \underline{B}_{C K}$. Hence, if creditors coordinate on the lowest possible price, the government faces a positive price for a non-trivial but truncated domain of debt issuances. We shall discuss this in more depth in Section 2.8.

As $V_{E G}^{R}$ lies above $V_{E G}^{D}+\sigma$ at $B^{\prime}=0$, the Eaton-Gersovitz price is valid for all $B^{\prime} \leq \bar{B}_{E G}$; that is $\mathbb{B}_{E G}=\left[0, \bar{B}_{E G}\right]$. Thus, the distinction with Panel (a) is that in Panel (b) the ColeKehoe price schedule has a restricted domain, while the Eaton-Gersovitz price domain is no longer truncated on the left. As was the case in Panel (a), there are three supportable equilibrium price schedules over part of the domain in Panel (b). Specifically, for $B^{\prime} \in$ $\mathbb{B}_{C K} \cap \mathbb{B}_{E G}$, there is an interior equilibrium price.

\subsection{Equilibrium Beliefs and Prices}

We now discuss how we map the possible equilibrium prices to the creditor belief sunspot $\rho$. In particular, we consider three possible belief regimes, each roughly corresponding to one of the three types of prices discussed above. We index beliefs by the exogenous state variable $\rho \in\{P, C, O\}$. The element "P" denotes pessimistic (or "worst-case") beliefs, "O" denotes optimistic (or "best-case") beliefs, and "C" denotes "concerned." Note that these beliefs differ in regard to the imminent repayment of maturing debt; beliefs over future outcomes are held fixed, although it is straightforward to introduce persistence in belief regimes. ${ }^{13}$

For all beliefs, $q\left(s, B^{\prime}\right)=R^{-1}$ for $B^{\prime} \leq 0$. For expositional simplicity, we omit this domain from the characterizations below. It is also useful to define $q_{I}\left(Y, B, B^{\prime}\right)$ as the largest interior

\footnotetext{
${ }^{13} \mathrm{It}$ is also straightforward to induce cross-country contagion, as is commonly observed during debt crises, either through correlation in the inter-period shock $\epsilon$ or through the draw of the belief regime $\rho$.
} 
Figure 4: Price Schedules

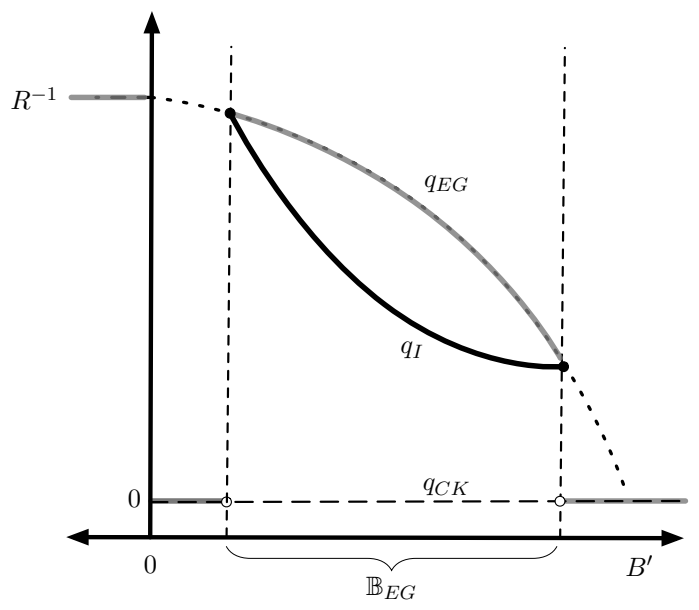

(a) Canonical "Crisis Zone"

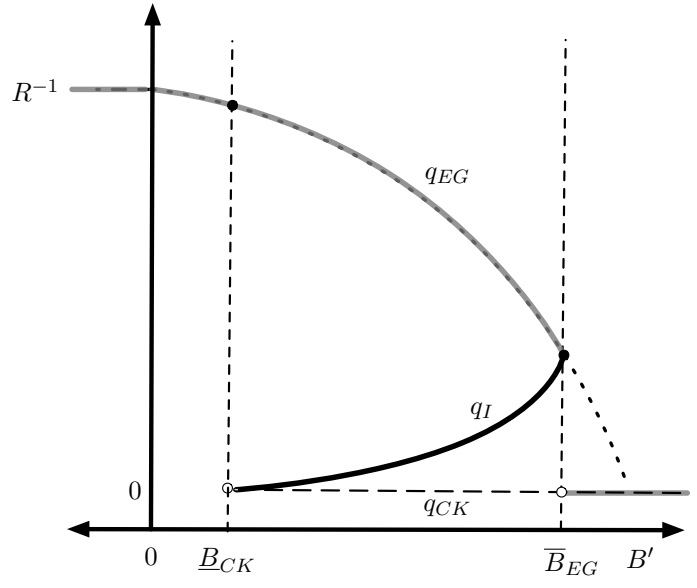

(b) Extended "Crisis Zone"

Price schedules associated with Figure 3 Panels (a) and (b), respectively. The downward sloping dashed line is $q_{E G}$ and the horizontal line at 0 is $q_{C K}$. The "optimistic" price schedule is the shaded line, which overlaps with $q_{E G}$ on $\mathbb{B}_{E G}$ in Panel (a) and $B^{\prime} \leq \bar{B}_{E G}$ in Panel (b). The "pessimistic" price schedule is zero for $B^{\prime}>0$ in Panel (a) and for $B^{\prime}>\underline{B}_{C K}$ in Panel (b), and $q_{E G}$ otherwise. The "concerned" price schedule is labelled $q_{I}$ on the domain where it differs from the optimistic price.

price, when an interior price exists: ${ }^{14}$

$$
q_{I}\left(Y, B, B^{\prime}\right)=\max _{\epsilon \in[0,1]}\left\{F(\epsilon) q_{E G}\left(B^{\prime}\right) \text { s.t. Equation (13) holds }\right\}
$$

Recall that the above analysis established conditions under which the interior price, when it exists, is unique, in which case the max operator just returns this price.

If $\rho=O$, then creditors coordinate on the highest possible equilibrium price for each state $\left(Y, B, B^{\prime}\right){ }^{15}$ In particular, $q\left(s, B^{\prime}\right)$ evaluated at $\rho=O$ equals $q_{E G}\left(B^{\prime}\right)$ if $B^{\prime} \in \mathbb{B}_{E G}(Y, B)$. If $B^{\prime}$ lies outside $\mathbb{B}_{E G}$, then the EG price is not supportable, and we assume creditors coordinate on the highest interior price $\left(q_{I}\right)$, if one exists, and, if no interior price exists, creditors coordinate on zero. From Proposition 2, we know that as $\sigma \rightarrow 0$, there is no interior price if $q_{E G}\left(B^{\prime}\right)$ is not supportable, and hence this implies the price is unambiguously zero for $B^{\prime}>0$ such that $B^{\prime} \notin \mathbb{B}_{E G}$.

Panels (a) and (b) of Figure 4 depict the price selection associated with the scenarios of the respective panels of Figure 3. Figure 4 assumes $\sigma \rightarrow 0$ for expositional simplicity.

\footnotetext{
${ }^{14}$ Note that solutions to equation (13) are the zeros of a continuous function, and hence constitute a closed set. Thus, the maximal element is well defined.

${ }^{15}$ Creditor beliefs cannot be manipulated directly by the government through its actions; that is, belief regimes are not conditional on $B$ or $B^{\prime}$. Nevertheless, the sensitivity of prices to beliefs varies with $B^{\prime}$ and this matters for optimal policy.
} 
The downward sloping dotted line is $q_{E G}\left(B^{\prime}\right)$. The shaded portion of that line depicts the optimistic price schedule when $B^{\prime} \in \mathbb{B}_{E G}$. Recall that for Figure 3 Panel (a), $\underline{B}_{E G}>0$, and hence there is an interval in the neighborhood above $B^{\prime}=0$ in which the EatonGersovitz price is not sustainable in equilibrium. As $\sigma \rightarrow 0$, Proposition 2 states that the only sustainable price on this domain is zero. For $B^{\prime} \in \mathbb{B}_{E G}$, the optimistic price schedule is $q_{E G}$. For $B^{\prime}>\bar{B}_{E G}$, the only sustainable price is again zero for small $\sigma$. In Panel (b) of Figure 3, we have $\underline{B}_{E G}=0$, and hence the optimistic price schedule tracks $q_{E G}$ for all $B^{\prime} \leq \bar{B}_{E G}$ in Panel (b) of Figure 4.

If $\rho=P$, then creditors coordinate on the lowest possible equilibrium price. Specifically, for $\rho=P$ and $B^{\prime}>\underline{B}_{C K}(Y, B)$, we have $q\left(s, B^{\prime}\right)=0$. For $B^{\prime}<\underline{B}_{C K}$, a zero price is not sustainable, and we set the price to $q_{I}$ if an interior price exists and $q_{E G}$ otherwise. For $B^{\prime}=\underline{B}_{C K} \equiv \inf \mathbb{B}_{C K}(Y, B)$, we set $q$ equal to a strictly positive price (either $q_{I}>0$ or $q_{E G}$ ); otherwise, the domain on which prices are strictly positive is open as $B^{\prime} \uparrow \underline{B}_{C K}$, and the optimal debt issuance policy may not be well defined.

In Panel (a) of Figure 4, the pessimistic price schedule is the horizontal dashed line at zero. Recall that in Figure 3 Panel (a) we depicted the canonical Cole-Kehoe Crisis Zone with $\underline{B}_{C K}=0$. Hence, a zero price is supportable for all $B^{\prime}>0$. In panel (b), however, $\underline{B}_{C K}>0$. Hence, the pessimistic beliefs track $q_{E G}$ for a non-trivial portion of the positive domain. As depicted, our selection ensures that $q$ is upper semi-continuous at $\underline{B}_{C K}$, and hence the zero price applies only for $B^{\prime}>\underline{B}_{C K}$.

If $\rho=C$, creditors focus on the within-period uncertainty and coordinate on the largest interior price, if one exists (and otherwise coordinate on the optimistic price). In particular,

$$
q\left(Y, B, \rho=C, B^{\prime}\right)=\left\{\begin{array}{l}
q_{I}\left(Y, B, B^{\prime}\right) \text { if } q_{I}\left(Y, B, B^{\prime}\right)>0 \\
q\left(Y, B, \rho=O, B^{\prime}\right) \text { otherwise }
\end{array}\right.
$$

where, as with $\rho=P$, we restrict $q_{I}>0$ to ensure a well-behaved budget set. Hence, for concerned beliefs, creditors coordinate on the price associated with the highest supportable indifference thresholds. The coordination on the highest root is chosen so that if the boundary case of $\tilde{\epsilon}=1$ satisfies (13), then $q_{E G}$ is the equilibrium price. We will return to this feature when we discuss the government's debt issuance policy below. As established in Proposition 2 , if $\sigma$ is small, then there is at most one interior price, and this additional level of selection is without loss.

In Panel (a) of Figure 4, we have a well defined interior price on $\mathbb{B}_{E G}$. As the government is indifferent to default when facing $q_{E G}$ at the boundaries of this domain, the interior price coincides with $q_{E G}$ at $\underline{B}_{E G}$ and $\bar{B}_{E G}$. On the interior of $\mathbb{B}_{E G}$, there is a strictly interior price. 
In Panel (b), an interior price is only sustainable on $\left[\underline{B}_{C K}, \bar{B}_{E G}\right]$. At $\underline{B}_{C K}$, the government is indifferent to default at the zero price. Hence, $q_{I}$ approaches zero as $B^{\prime} \downarrow \underline{B}_{C K}$. As before, $q_{I}$ approaches $q_{E G}$ as $B^{\prime} \uparrow \bar{B}_{E G}$.

The fact that $q_{I}(Y, B, \cdot)$ is non-monotonic in $B^{\prime}$ reflects the two sources of risk. As the government auctions more debt it relaxes the burden on repaying maturing bonds. For $B>0$, concavity of $u$ implies that more auction revenue increases $u\left(Y-B+q B^{\prime}\right)$ more than $u\left(Y+q B^{\prime}\right)$, raising the likelihood of repayment at settlement. However, an increase in $B^{\prime}$ may lower the continuation value and increase the probability of default. The net effect is ambiguous. In Panel (a), we depict the latter effect dominating and $q_{I}$ is always decreasing. In Panel (b), the former effect dominates and the interior price is increasing in $B^{\prime}$.

The non-monotonicity reflects that the interior price captures elements of both a failed auction and the standard Eaton-Gersovitz concerns about future default. That is, creditors worry whether the government is raising enough auction revenue to repay maturing debt in the current period as well as about whether the government will default in the next period. The pessimistic beliefs put all the weight on the former, generating a zero price. The optimistic beliefs put all the weight on the latter, generating the Eaton-Gersovitz price. And the interior price is a mixture of the two.

The price schedule depends on maturing debt $B$ as well as new issuances, and the comparative static with respect to $B$ is also not necessarily monotone. While it is perhaps counter-intuitive that more legacy debt is not always a negative for current spreads, this property is the combination of two intuitive forces. On the one hand, a lower $B$ reduces the scope for negative outcomes (either $q_{C K}$ or $q_{I}$ ), favoring the Eaton-Gersovitz price. This may generate a higher price conditional on $\rho \neq O$, as the only sustainable price becomes $q_{E G}$ as $B$ falls. However, if an interior price exists, it may increase as $B$ declines. This reflects that the point of indifference between repayment and default occurs at a lower auction price the smaller is outstanding debt. That is, governments with low amounts of legacy debt are less prone to a crisis, but conditional on such a government having a crisis, it will involve a relatively severe spike in spreads to make default a credible threat. ${ }^{16}$

Note that under any of the beliefs discussed above, the government may face a discontinuous price schedule. Clearly, the government will never issue $B^{\prime}$ just to the right of a discontinuous drop in the price schedule when the continuation value is decreasing in $B^{\prime}$.

\footnotetext{
${ }^{16}$ More precisely, the comparative statics are such that the interior price increases in $B$ for small $\sigma$. Recall that this is the case depicted in Panel (a) of Figure 2, and an increase in $B$ shifts the increasing part of the $\tilde{F}$ curve to the right, increasing the point of intersection with the 45-degree line. For large $\sigma$, there may be multiple interior prices with differing comparative statics (panel (b) of Figure 2), or a unique interior price that is the maximal price sustainable with any beliefs (panel (c)) that has the opposite comparative static to the small $\sigma$ case.
} 
Such a debt issuance raises less revenue and depresses the continuation value. The next subsection discusses optimal debt issuance and formally confirms that intuition. Moreover, we establish that there are conditions under which the government will never issue debt at any part of the domain with a strictly interior price. That is, the government will optimally choose a debt level that zeroes out intra-period default risk.

\subsection{Debt Policy Functions}

We now discuss the government's optimal debt issuance policy given an equilibrium price schedule and continuation value. We will show that for all three belief regimes, as $\sigma \rightarrow 0$, the government either issues at Eaton-Gersovitz prices or defaults with probability one. The impact of creditor beliefs is on what level of issuances (if any) the government undertakes at auction. Observed equilibrium prices will differ across beliefs due to the differences in debt issuances, but the observed equilibrium prices will all be points on the best possible price schedule.

We begin with perhaps the most surprising insight. Namely, under certain general conditions, in equilibrium the government will never issue debt at a strictly interior price:

Proposition 5. For a given $s \in S$ with $\rho=C$, consider two possible debt issuances $\left\{B_{1}^{\prime}, B_{2}^{\prime}\right\}$ with $q\left(s, B_{i}^{\prime}\right)$ interior $i=1,2$. If (i) $\frac{q\left(s, B_{1}^{\prime}\right)}{q_{E G}\left(B_{1}^{\prime}\right)} \leq \frac{q\left(s, B_{2}^{\prime}\right)}{q_{E G}\left(B_{2}^{\prime}\right)}$, and (ii) $q\left(s, B_{1}^{\prime}\right) B_{1}^{\prime} \leq q\left(s, B_{2}^{\prime}\right) B_{2}^{\prime}$, then $B_{2}^{\prime}$ weakly dominates $B_{1}^{\prime}$ as a policy choice, and strictly dominates if either of the two inequalities is strict.

The first condition says that the intra-period risk of $B_{2}^{\prime}$ is less than that of $B_{1}^{\prime}$. In particular, if $\tilde{\epsilon}_{i}, i=1,2$, are the respective thresholds from equation (13), then $F\left(\tilde{\epsilon}_{2}\right) \geq F\left(\tilde{\epsilon}_{1}\right)$, making it less likely the government defaults at settlement after issuing $B_{2}^{\prime}$. The second condition says that $B_{2}^{\prime}$ raises more auction revenue than $B_{1}^{\prime}$.

Proposition 5 states that, when choosing over the interior price schedule, the government favors less intra-period risk and more auction revenue, all else equal. Applying this result to Figures 3 and 4, the government strictly prefers to issue at $\bar{B}_{E G}$ instead of any debt level that fetches an interior price and raises less revenue:

Corollary 1. For a given $s \in S$ with $\rho=C$, suppose there exists $\bar{B}_{E G}=\max \mathbb{B}_{E G}$ such that $q\left(s, \bar{B}_{E G}\right)=q_{I}\left(s, \bar{B}_{E G}\right)=q_{E G}\left(\bar{B}_{E G}\right)$. Then for any $B^{\prime}$ such that $(i) q\left(s, B^{\prime}\right)<q_{E G}\left(B^{\prime}\right)$ and (ii) $q\left(s, B^{\prime}\right) B^{\prime} \leq q_{E G}\left(\bar{B}_{E G}\right) \bar{B}_{E G}$, the government finds $\bar{B}_{E G}$ strictly preferable to $B^{\prime}$.

At $\bar{B}_{E G}$, the auction occurs at the Eaton-Gersovitz price, but at a debt level that is elevated relative to $B_{E G}^{*}$. By issuing additional debt, the government can eliminate the risk of not 
repaying maturing debt at settlement, but at the cost of raising the probability of default next period.

Proposition 5 implies that the government will never issue debt on the interior of $\mathbb{B}_{E G}$, unless $\bar{B}_{E G}$ is on the wrong side of the debt Laffer curve. On the interior, the government receives a low price due to concern about intra-period risk. As the government is indifferent at the margin to such risk, it has an incentive to choose debt that minimizes intra-period risk. The proposition says that the government will issue debt such that there is zero intra-period risk. ${ }^{17}$ That is, it will issue debt only at the EG price in equilibrium. Hence, the primary impact of concerned beliefs is not to deliver an interior price on the equilibrium path, but rather to push the government to issue an alternative level of debt. In particular, it may lead the government to issue more debt than it would under the optimistic beliefs. This result will also be echoed in the policy functions of the quantitative model in Section 3; in particular, see Figure 6.

For the case depicted in panel (a) of Figure 3, the proposition states that the government will issue at $\bar{B}_{E G}>B_{E G}^{*}$. In particular, the result states that the points on the interior of $\left(\underline{B}_{E G}, \bar{B}_{E G}\right)$ are dominated by the right end point. Given that $V_{E G}^{D}$ is strictly increasing for $B^{\prime} \leq \bar{B}_{E G}, \bar{B}_{E G}$ also dominates $\underline{B}_{E G}$. The proposition leaves open the possibility that the government may issue $B^{\prime}>\bar{B}_{E G}$, if that raises more revenue at auction. In that case, the government is attracted by the extra revenue, which it keeps in the case of default. However, Proposition 2 states that as $\sigma \rightarrow 0$, the points outside of $\mathbb{B}_{E G}$ have a price that approaches zero, and hence these alternatives are also dominated.

For the case of panel (b) of Figure 3, the government will issue either $\underline{B}_{C K}$ or $\bar{B}_{E G}$, assuming $B^{\prime}>\bar{B}_{E G}$ does not raise additional revenue. Issuing $\underline{B}_{C K}$ yields the EatonGersovitz price, as even at a zero price the government does not default. It is in general ambiguous whether the repayment value at $\underline{B}_{C K}$ is greater or less than the repayment value at $\bar{B}_{E G}$. The proposition establishes that issuances on the interior of $\left(\underline{B}_{C K}, \bar{B}_{E G}\right)$ are dominated by $\bar{B}_{E G}$. In the case of panel (b), therefore, the government may over-issue or underissue relative to $B_{E G}^{*}$ when facing concerned beliefs. The common implication is that the government's debt issuance yields the Eaton-Gersovitz price in equilibrium, but the quantity of issuance is distorted relative to $B_{E G}^{*}$.

For large $\sigma$, there may be an interior price at $B^{\prime}>\bar{B}_{E G}$ which raises enough additional revenue that it warrants risking default at settlement (and keeping the revenue) rather than issuing $\bar{B}_{E G}$ and securing the EG price. In our simulations of the quantitative model

\footnotetext{
${ }^{17}$ This intuition uses the fact that fixing $B^{\prime}$, the government always prefers a better price in exchange for a lower probability of intra-period default. It leaves out the impact on the continuation value from increasing $B^{\prime}$. The proof establishes that, under concerned beliefs, the former effect dominates the latter.
} 
presented in Section 3, issuance at $B^{\prime}>\bar{B}_{E G}$ under concerned beliefs does not happen in equilibrium.

Slow Motion Crises: Despite the i.i.d. beliefs and the static nature of multiplicity, Proposition 5 states that concern about rollover risk can lead to a prolonged crisis. If $\bar{B}_{E G}$ is preferable and $\bar{B}_{E G}>B_{E G}^{*}$, then concerned beliefs lead to "over borrowing" relative to optimistic beliefs. While the price obtained is the Eaton-Gersovitz price, it will imply high spreads due to the greater level of debt issuance. The concerned beliefs induce over borrowing because the creditors are worried that if the government were to issue less debt, it would not have adequate revenue to credibly repay maturing debt at settlement. In this case, current over borrowing can lead to a prolonged, slow motion crisis in which the government over issues today, raising the possibility of future default. This is reminiscent of the dynamics of Lorenzoni and Werning (2013)'s slow-moving crises, but in our case the multiplicity is entirely static. In particular, conditional on issuing $\bar{B}_{E G}$, the equilibrium price is unique. However, the off-equilibrium beliefs about intra-period risk lead the government to issue more debt than is optimal under optimistic beliefs. In the quantitative analysis, we shall see that such crises are indeed a frequent outcome along the equilibrium path.

We now turn to debt issuance under the more familiar optimistic and pessimistic beliefs. Under optimistic beliefs, the government faces the best supportable price schedule. For $\sigma \rightarrow 0$, this implies the government will optimize over $B^{\prime}(-\infty, 0] \cup \mathbb{B}_{E G}$ conditional on the $q_{E G}\left(B^{\prime}\right)$ price schedule. This is similar to the standard problem under intra-period commitment, with the only difference introduced by the current timing being that not all $B^{\prime}$ are consistent with guaranteed repayment at settlement. That is, $\mathbb{B}_{E G}$ does not necessarily include all $B^{\prime}$ such that $q_{E G}\left(B^{\prime}\right)>0$, as the government has the option to default immediately after the auction. ${ }^{18}$ As in the standard model, if $Y$ is low enough and $B$ high enough, the government defaults with probability one. In that case, the value of default dominates any achievable repayment value. This can be considered a "fundamental" default in the sense that default occurs regardless of creditor beliefs.

Under pessimistic beliefs, the government faces a price of zero for $B>\underline{B}_{C K}$. If $\underline{B}_{C K}=0$, we are in the standard Cole-Kehoe crisis scenario. That is, the government cannot issue any amount of debt at a positive price. It therefore has the option of purchasing assets and repaying $B$ or defaulting with probability one. If $\underline{B}_{C K}>0$, there is a range of debt that carries a strictly positive price. As $\sigma \rightarrow 0$, this price becomes the Eaton-Gersovitz price. Issuing a small amount of debt at this price may dominate outright default (or purchasing

\footnotetext{
${ }^{18}$ For large $\sigma$, the government facing optimistic creditors may choose to issue debt at an interior price; in particular, for large $\sigma$ there are debt levels which cannot sustain $q_{E G}$ but have a strictly positive price.
} 
assets). If so, then the equilibrium outcome of pessimistic beliefs is not default but truncated debt issuance.

Sudden Stops: This last outcome corresponds to "forced deleveraging" or a "sudden stop" crisis. If $B_{C K}>0$, even under pessimistic beliefs, the government can issue some debt at strictly positive prices. However, it cannot issue to the level of the optimistic beliefs optimum, $B_{E G}^{*}$ (see Panel (b) of Figure 3). For this to be an equilibrium outcome, $(Y, B)$ must be more favorable than in the canonical rollover crisis, but at the same time, $Y$ must be low enough and $B$ high enough that $\underline{B}_{C K}(Y, B)<\bar{B}_{E G}$. Just as in the rollover crisis, whether or not the government is forced to delever depends upon the realization of the sunspot variable. Interestingly, the forced deleveraging choice may also be the equilibrium outcome under concerned beliefs. From Proposition 5 and the subsequent discussion, we know that as $\sigma \rightarrow 0$, the government will issue either at $\bar{B}_{E G}$ or the pessimistic-beliefs optimal issuances. Which it chooses depends on whether $V_{E G}^{R}\left(Y, B, \underline{B}_{C K}\right) \gtrless V_{E G}^{R}\left(Y, B, \bar{B}_{E G}\right)$. In the quantitative analysis, we show that at low levels of debt, sudden stops do occur, but over-borrowing/slow-motion crisis is the norm for the majority of the ergodic distribution.

\subsection{Long-Term Debt and Buybacks}

The insights from the one-period bond model carry over to bonds of longer duration, although there are quantitative differences discussed in Section 3. The new conceptual margin introduced by extended maturity is that the sovereign can repurchase existing debt. This raises the issue of how creditor beliefs affect incentives and prices for debt buybacks.

We assume that the sovereign borrows by issuing long-term non-contingent bonds. These bonds pay a coupon every period up to and including the period of maturity, which, without loss of generality, we normalize to the risk-free rate $r^{*}$. With this normalization, a risk-free bond will have an equilibrium price of one. For tractability, we consider a bond with random maturity, as in Leland (1994). ${ }^{19}$ We assume there is only one maturity traded and $\lambda$ is a primitive parameter of the environment.

The government's value functions are the same as in the one-period case, except that consumption in the event of repayment is $Y-\left(r^{*}+\lambda\right) B+q\left(s, B^{\prime}\right)\left[B^{\prime}-(1-\lambda) B\right]$ and in default is $Y+q\left(s, B^{\prime}\right)\left[B^{\prime}-(1-\lambda) B\right]$. When $B^{\prime}-(1-\lambda) B>0$, the government is adding to its (non-maturing) debt stock and the situation is similar to the one-period debt case analyzed previously. That is, the price of newly issued debt depends on investor beliefs about repayment at settlement of coupon and maturing principal $\left(r^{*}+\lambda\right) B$.

\footnotetext{
${ }^{19}$ See also Hatchondo and Martinez (2009), Chatterjee and Eyigungor (2012) and Arellano and Ramanarayanan (2012).
} 
More interestingly, when $B^{\prime}-(1-\lambda) B<0$ the government is buying back some of its debt rather than issuing more debt. Since the buyback takes place at the time of the auction, any funds spent on the buyback are sunk.

The analog of our interior price condition with one period debt (13) is now given by

$$
\begin{aligned}
\sigma \tilde{\epsilon}= & u\left(Y-\left(r^{*}+\lambda\right) B+\tilde{q} \times\left[B^{\prime}-(1-\lambda) B\right]\right)-u\left(Y+\tilde{q} \times\left[B^{\prime}-(1-\lambda) B\right]\right) \\
& +\beta \mathbb{E}\left[V\left(s^{\prime}\right) \mid s, B^{\prime}\right]-\beta \mathbb{E} V^{D}\left(s^{\prime}\right)
\end{aligned}
$$

where $\tilde{q}=F(\tilde{\epsilon}) q_{E G}$. Note that the right-hand side of (16) is decreasing in $q$ if there are buybacks $\left(B^{\prime}<(1-\lambda) B\right)$, hence the right-hand side is decreasing in $\tilde{\epsilon}$. Therefore, with buybacks, there can be only one equilibrium price for a fixed $\left(s, B^{\prime}\right)$. This leads to the following result:

Proposition 6. Given $s$ and $B^{\prime}$, if $B^{\prime}<(1-\lambda) B$, the equilibrium price $q\left(s, B^{\prime}\right)$ is unique.

Even though the equilibrium buyback price is unique, it could still reflect positive intraperiod default risk because the sovereign still has to service outstanding debt at settlement. However, the next proposition asserts that if by reducing its buybacks the sovereign can reduce both intra-period risk and the amount being paid out to lenders, it is optimal for it do so. This effectively means that when buybacks occur, they occur at EG prices.

Proposition 7. Consider two possible buybacks $\left\{B_{1}^{\prime}, B_{2}^{\prime}\right\}$ with $q\left(s, B_{i}^{\prime}\right)$ interior $i=1,2$, $B_{i}^{\prime}<(1-\lambda) B$ and $B_{1}^{\prime}>B_{2}^{\prime}$. If (i) $\frac{q\left(s, B_{1}^{\prime}\right)}{q_{E G}\left(B_{1}^{\prime}\right)} \geq \frac{q\left(s, B_{2}^{\prime}\right)}{q_{E G}\left(B_{2}^{\prime}\right)}$ and (ii) $q\left(s, B_{1}^{\prime}\right)\left[B_{1}^{\prime}-(1-\lambda) B\right] \geq$ $q\left(s, B_{2}^{\prime}\right)\left[B_{2}^{\prime}-(1-\lambda) B\right]$ then $B_{1}^{\prime}$ weakly dominates $B_{2}^{\prime}$ and does so strictly if either of these two inequalities is strict.

\section{$3 \quad$ Numerical Examples}

A key insight from the analytical model is that, when confronted with concerned beliefs, the government adjusts debt issuances in order to avoid intra-period risk. This section verifies that this feature carries over to richer, quantitative versions of the model. ${ }^{20}$ We do so in both a one-period debt model as well as a model with longer maturity, the former to hew closely to the analytical model and the latter as a bridge to the recent quantitative literature building on Hatchondo and Martinez (2009) and Chatterjee and Eyigungor (2012).

Given our focus on self-fulfilling debt crises, it is important to accurately capture the vulnerability of sovereigns to rollover risk. Governments in crisis often face large interest

\footnotetext{
${ }^{20}$ The computer code for the computation of the model can be found at https://github.com/ zstangebye/self_fulfilling_crises_revisited.git.
} 
and principal payments relative to available resources, despite the fact that average maturity is on the order of five years in many emerging markets and European crisis countries. In practice, there are discrete "lumps" in the maturity profile, where debt coming due in a particular month is substantially larger than the amount implied by face value and average maturity, in part due to the disproportionate issuance of bonds with maturities less than or equal to 12 months.

Mexico and Italy are both good examples. In the first quarter of 1995, Mexico's maturing debt payments were nearly 90 percent of tax revenue. ${ }^{21}$ If we exclude the very short maturity Cetes, the ratio of debt due to tax revenue is still 66\%. In 2011Q4, Italy had scheduled debt payments over the next year totaling three-quarters of tax revenue. These large debt payments as a fraction of tax revenue made them vulnerable to a failed auction. To match this feature in our model, we focus on interest and maturing debt relative to revenue. We now describe how we calibrate the model to capture this vulnerability. We focus on Mexico in the text, and report an alternative calibration for Italy in the appendix, along with some robustness experiments.

We assume the government has access to a constant share of the endowment $\tau Y{ }^{22}$ Letting $G$ be government expenditure, the budget constraint is: $G+\hat{B}=\tau Y+q\left(s, \hat{B}^{\prime}\right) \hat{B}^{\prime}$, where $\hat{B}$ is face value of debt. Dividing through by $\tau$ and letting $C \equiv G / \tau$ and $B \equiv \hat{B} / \tau$, we obtain the standard budget constraint used throughout the paper. More precisely, we consider $C / Y$ to be government expenditure and $B / Y$ to be the face value of debt, both normalized by tax revenue.

Many aspects of the calibration of our model are similar to the literature. The model period is a quarter. We make standard parameter choices for the risk-free rate and preferences. The quarterly risk-free rate is set to $1 \%$; the sovereign has time-separable power-utility preferences with CRRA $=2$; and we follow Aguiar and Gopinath (2006) in setting $\beta=0.8$.

Default involves a proportional loss of endowment as well as temporary exclusion from financial markets. Exclusion ends with a Poisson hazard rate, after which the government is in good credit standing with zero debt. Following Aguiar and Gopinath (2006), we set the quarterly Poisson re-entry probability in the default state to $12.5 \%$. Also following Aguiar and Gopinath $(2006,2007)$, the rate of growth of the government's endowment is modeled as the sum of an $\mathrm{AR}(1)$ process $g_{t}$ and a transitory $\mathrm{MA}(1)$ error $\eta_{t}: \ln Y_{t}-\ln Y_{t-1}=g_{t}+\eta_{t}$, where $g_{t}=\left(1-\rho_{g}\right) \mu_{g}+\rho_{g} g_{t-1}+\sigma_{g} \epsilon_{t}, \eta_{t}=\sigma_{s}\left[s_{t}-s_{t-1}\right]$ and $\epsilon_{t}, s_{t} \sim N(0,1)$. This is equivalent to an environment with stochastic trend growth and i.i.d. transitory shocks. We use quarterly

\footnotetext{
${ }^{21}$ The debt due is reported in Cole and Kehoe (1996). The tax revenue is from the OECD.

${ }^{22}$ For reference, the average revenue-to-GDP ratio for Mexico is 26\% in 1990Q1-2020Q3 and is $18 \%$ in 1995Q1. However, as discussed, we do not use these numbers directly in the calibration.
} 
Mexican real GDP data for 1980Q1-2020Q3 and estimate $\mu_{g}=.0033, \rho_{g}=.331, \sigma_{g}=.014$ and $\sigma_{s}=.011$.

We turn now to the less standard aspects. To highlight our novel approach to crises, we set the probability of $\rho=P$ to 0 and focus on the equilibrium with transitions between optimistic and concerned belief regimes, $\rho \in\{C, O\}$. We continue to assume that $\rho$ is i.i.d. over time, and select the probability $\rho=C$ and the proportional default cost $d$ to match two key empirical moments for Mexico. We also report the canonical CK case of $\rho \in\{P, O\}$ and $\rho \in\{O\}$ for reference. To capture limiting behavior as $\sigma$ approaches zero, we assume positive but minimal intra-period risk. Specifically, $\sigma=0.0001$ and $\epsilon$ is uniform on $[0,1] .{ }^{23}$

We calibrate $d$ and the probability of $\rho=C$ by matching two moments. One of these is the standard deviation of the Mexican EMBI sovereign spread, which, for the available sample period of 1994Q1-2020Q3, is 2.3\%. The second moment captures Mexico's vulnerability to a rollover crisis. Specifically, for Mexico, the face value of debt to quarterly tax revenue is 1.8 in 1995Q1, and this is the 97.5th percentile of the 1990Q1-2020Q3 sample. Recalling that debt payments to revenues were 0.66 in 1995Q1, the second targeted moment is debt payment totaling $66 \%$ of resources at the 97.5th percentile of the ergodic distribution of debt. For the short-term debt model, debt payments and face value must coincide, but for long-term debt model we choose additional parameters (discussed in Section 3.2) to match the ratio of face value to revenue of 1.8 as well. ${ }^{24}$

For the one-period bond model, targeting these two moments leads to $d=0.176$ and probability of encountering a concerned belief regime of $0.8 \%$ (i.e., lenders become concerned about intra-period risk once every 32 years). The long-term bond calibration, reported below, involves higher costs of default and lower probability of concerned beliefs.

\subsection{One-period Debt}

The upper panel of Table 1 reports the one-period bond model, and the first row reports the key moments of the base one-period debt model (the next two rows pertain to alternative belief specifications and will be discussed later). The calibration implies that a default occurs once every two hundred years, which is arguably too low relative to the data but a well-known feature of one-period debt models that do not have implicit "debt forgiveness" in low endowment states via a non-linear default cost. ${ }^{25}$ Still, the low default frequency does not make it impossible to match the volatility of spreads. The reason is that when the

\footnotetext{
${ }^{23}$ Model moments and equilibrium properties are not sensitive to the choice of $\sigma$ as long as it is small; in Section C.3 in the appendix, we report results for $\sigma 100$ times larger.

${ }^{24}$ Holding constant payments coming due, longer maturity raises the fraction consisting of interest payments, necessitating a larger face value and effective debt burden.

${ }^{25}$ In Tomz and Wright (2013) sample of countries, default occurs roughly once every fifty years.
} 
concerned regime occurs, the government avoids default by issuing a significant amount of debt at high yields, exactly as discussed in Corollary 1. The final column reports the ratio of the standard deviations of the HP-detrended log consumption and log output, and generates the expenditure volatility that is characteristic of emerging economies. ${ }^{26}$

Table 1: Simulated Moments: One-Period and Long-Term Bonds

\begin{tabular}{|c|c|c|c|c|}
\hline Model & $\begin{array}{c}97 \% \text { ile } \\
\text { DebtPmt/Rev } \\
\text { (Quarterly) }\end{array}$ & $\begin{array}{c}\text { Default } \\
\text { Frequency } \\
\text { (Annualized) }\end{array}$ & $\begin{array}{c}\operatorname{StDev}\left(r-r^{*}\right) \\
(\text { Annualized })\end{array}$ & $\frac{\operatorname{StDev}(\ln c)}{\operatorname{StDev}(\ln y)}$ \\
\hline & \multicolumn{4}{|c|}{ One-Period Bonds } \\
\hline Base, $\rho \in\{O, C\}$ & $66 \%$ & $0.5 \%$ & $2.3 \%$ & 1.15 \\
\hline Optimistic, $\rho \in\{O\}$ & $66 \%$ & $0.2 \%$ & $0.1 \%$ & 1.14 \\
\hline \multirow[t]{2}{*}{ Cole-Kehoe, $\rho \in\{O, P\}$} & $61 \%$ & $3.5 \%$ & $0.3 \%$ & 1.09 \\
\hline & \multicolumn{4}{|c|}{ Long-Term Bonds } \\
\hline Base, $\rho \in\{O, C\}$ & $66 \%$ & $5.2 \%$ & $2.3 \%$ & 1.51 \\
\hline Optimistic, $\rho \in\{O\}$ & $67 \%$ & $4.7 \%$ & $1.0 \%$ & 1.53 \\
\hline Cole-Kehoe, $\rho \in\{O, P\}$ & $29 \%$ & $0.0 \%$ & $0.0 \%$ & 1.29 \\
\hline
\end{tabular}

To further understand these model moments and to relate them to the analytical model, it is useful to consider the equilibrium price and policy functions. Figure 5 depicts the quantitative version of Figure 4. In each panel, the thin black dashed line is the reference price schedule $q_{E G}$ introduced in the analytical model; that is, it is the break-even price of a bond if creditors were certain of repayment at the current period's settlement. The thick solid black line is the optimistic price schedule and the thick grey dashed line is the concerned price schedule. All schedules are evaluated at the mean endowment growth.

Figure 5 reflects the same economics as Figure 4. In Panel (a), we are in the canonical Cole-Kehoe Crisis Zone: If the model were to incorporate pessimistic beliefs in the current period, the associated price schedule would be zero for all $B^{\prime}>0$. For low levels of future debt, $q_{E G}$ cannot be supported because insufficient revenue at today's auction makes repayment at the current period's settlement non-credible. So, zero is the only equilibrium price regardless of beliefs. There is a subset of the debt domain, labeled $\mathbb{B}_{E G}$, on which the Eaton-Gersovitz price schedule is supportable. On this domain, an interior price schedule is also a valid equilibrium outcome, and creditor beliefs determine which schedule is realized at auction. For larger values of future debt, prices fall to zero again, regardless of beliefs, as

\footnotetext{
${ }^{26}$ See Aguiar and Gopinath (2007) and Kaminsky et al. (2004) on the private and public expenditure volatility, respectively, that characterizes emerging markets.
} 
Figure 5: Price Schedules: Evaluated at Mean Endowment Growth

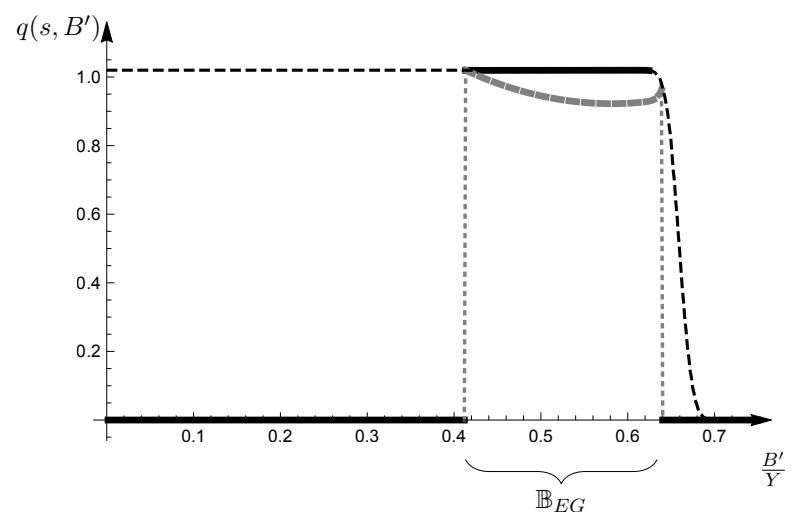

(a) Initial $B / Y=66 \%$ (Mean Debt-to-GDP)

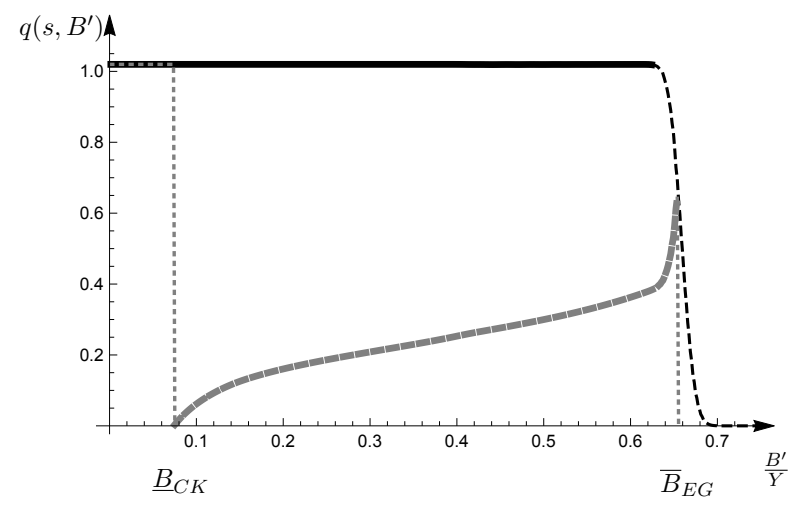

(b) Initial $B / Y=42 \%$

This figure is the counterpart of Figure 4 for the quantitative model. Panel (a) depicts the case of mean $g$ and mean $B / Y$. Panel (b) depicts mean $g$ and a low initial debt level.

the future debt burden is great enough to trigger immediate default. ${ }^{27}$

In Panel (b), legacy debt is at a level encountered along the transition path to the ergodic distribution. At this low level, and for debt issuances less than $\underline{B}_{C K}$ the Eaton-Gersovitz price is the only equilibrium price possible as the government is willing to repay even without auctioning new debt. If creditors coordinated on pessimistic beliefs, the price schedule would be $q_{E G}$ for $B^{\prime} / Y \leq \underline{B}_{C K}$ and zero otherwise. For $B^{\prime} / Y \in\left[\underline{B}_{C K}, \bar{B}_{E G}\right]$, three prices are consistent with equilibrium; namely, zero, the Eaton-Gersovitz price, and an interior price. For $B^{\prime} / Y>\bar{B}_{E G}$, the only supportable price is zero because future debt burden is too great.

Figure 6 depicts the government's policy function evaluated at the mean growth rate of endowment. The policy response to the optimistic price schedule delivers the familiar dynamics of quantitative Eaton-Gersovitz models: If the government were to consistently face optimistic beliefs, it would issue debt quickly to approach the mean debt-to-output ratio. Once debt is built up, endowment shocks induce small variation in debt levels until a sufficiently low endowment shock causes default.

The policy response to the concerned price schedule is markedly different and tracks the intuition provided in the discussion following Proposition 5, Corollary 1. At low initial debt levels and low issuances, the concerned price schedule overlaps with the optimistic schedule (see Figure 5b). Hence, the policies overlap on this domain in Figure 6. For initial debt levels between 33 and 41 percent of quarterly revenue, the concerned regime induces the

\footnotetext{
${ }^{27}$ Another factor in the zero price at high debt issuances is that the government keeps the period's auction revenue in default, making it more difficult to sustain a positive price for high $B^{\prime}$.
} 


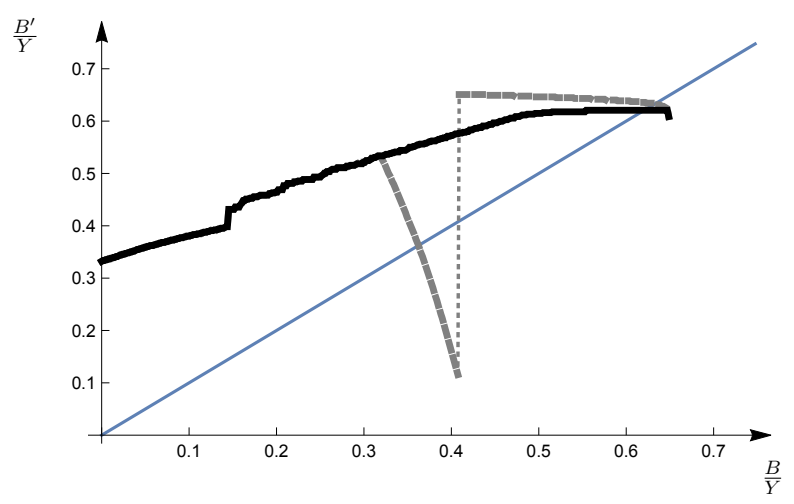

Figure 6: Debt-Issuance Policy Functions

Policy function for new debt issuances as a function of maturing debt, evaluated at the mean $g$. The monotonic black line is for optimistic beliefs, and the nonmonotonic blue line depicts the policy for concerned beliefs, which is identical to the former for low initial debt levels. The straight line is the $45^{\circ}$ line. Debt levels to the right of the depicted lines imply certain default.

government to truncate its debt issuances: low debt levels secure the Eaton-Gersovitz price and avoid intra-period risk. For the same reason (avoidance of intra-period risk), but with the opposite outcome, the government over issues (relative to the optimistic policy) for debt levels beyond 41 percent of the endowment. ${ }^{28}$

To summarize, higher debt levels increase future default risk under either belief regime. But under concerned beliefs, intra-period default risk is very sensitive to debt issuances, with relatively low levels of issuance generating higher risk due to concerns about whether the government has raised enough revenue to repay old debt at settlement. This countervailing force, absent under Eaton-Gersovitz timing, generates the flatter price schedule under concerned beliefs and induces the government to issue more debt.

While the concerned price schedule is flatter in the neighborhood of $\bar{B}_{E G}$, it is not high. That is, future default risk is significant, and this is reflected in spreads. In the base model, the average spread is $0.6 \%$, reflecting the overall low default rate. However, conditional on the concerned regime, the average spread is $25 \%$, which is roughly 50 times the unconditional mean; moreover, $31 \%$ of all defaults are immediately preceded by the concerned regime. ${ }^{29}$

\footnotetext{
${ }^{28}$ The upward jump discontinuity in the concerned-belief policy function at 0.41 induces another upward jump discontinuity in both policy functions at roughly 0.15 where (regardless of beliefs) the optimal debt issuance increases from below 0.41 to above. The discrete jump down in next period's expected marginal utility of consumption as $B^{\prime}$ crosses 0.41 causes the discrete jump up in debt issuance at $B=0.15$.

${ }^{29}$ Another $10 \%$ of defaults coincide with $\rho=C$ but these occur mostly for numerical reasons. Since $\bar{B}_{E G}$ is typically not exactly on the grid for $B / Y$, the discreteness in debt values causes default to sometimes
} 
Thus, the concerned regime frequently leads the government to over borrow and increases the risk of default next period.

We now turn to the two other rows of Table 1 pertaining to the one-period bond case. The "Optimistic" case explores the same environment, but without shifts in beliefs, i.e., the lenders maintain optimistic beliefs throughout. This alternative model features pricing and policy functions similar in shape and magnitude to the solid black lines in Figures 5 and 6, respectively. While it generates commensurate debt levels, this specification cuts the default rate by more than half and the spread volatility by a factor of 23 . The "Optimistic" case reveals that the possibility of the concerned regime, albeit rare in the base model, is pivotal in generating defaults and spread volatility. In the "Cole-Kehoe" case, the concerned belief regime is replaced with the pessimistic regime. The policy functions in this alternative model resemble the dashed grey lines in Figure 6 but without the overborrowing region. The endogenous response of the government is to de-lever slightly and, when beliefs shift, to default rather than overborrow. This behavior increases default frequency substantially relative to the base model but, since no overborrowing ever takes place, it reduces spread volatility significantly as well.

\section{$3.2 \quad$ Long-Term Debt}

In this section, we examine the case of long-term bonds. The motivation for this investigation is the well-known point, emphasized by Cole and Kehoe (2000) and others, that lengthening the maturity of debt is one way to eliminate rollover crises. Nevertheless, we show in this section that with plausible constraints on fiscal resources, rollover crises can persist with long-term debt.

For the long-term debt model, debt payments as a fraction of revenue is $(\kappa+\lambda) B$, where $\kappa$ is the coupon, $\lambda$ is the inverse maturity parameter and $B$ is the (revenue normalized) face value of inherited debt. We set $\kappa$ to $3 \%$. To pick $\lambda$, recall that Mexico's ratio of face value of debt to tax revenues was 1.8 in 1995Q1. This is consistent with the required debt payments of 0.66 if $\lambda=0.064$, or a maturity of approximately four years. With these choices for $\kappa$ and $\lambda$, the cost of default and probability $\rho=C$ was chosen to match the same two moments, namely, the standard deviation of spreads of $2.3 \%$ and debt-payment-to-revenue of $66 \%$ at the 97.5 th percentile of the debt distribution. This required $d=0.467$ and concerned probability of $0.44 \%$ quarterly, or roughly once every 57 years.

The simulated moments of the long-term bond case are reported in the lower panel of Table $1 .{ }^{30}$ The default frequency is now $5 \%$ annually, or once every 20 years, higher than the

dominate over-borrowing.

${ }^{30}$ The price schedules and policy functions for the long-term debt model are not depicted as they have 
average experience of emerging market economies. The elevated default frequency is a wellknown consequence of debt dilution, which induces the government to venture deeper into the default region. Importantly, the government remains exposed to belief shocks, and when the concerned regime materializes it overborrows just as in the one-period debt model. The overborrowing leads to a spike in spreads and sometimes to a default in the next period. ${ }^{31}$

The other alternatives in bottom panel of Table 1 show that the concerned belief regime is pivotal in generating spread volality just as in the one-period model. In the "Optimistic" case, debt levels are somewhat higher but the high cost of default lowers default frequency somewhat as well. More importantly, spread volatility declines by more than half because there are no spikes due to belief shocks. In the "Cole-Kehoe" case, the government's optimal response is to stay out of the default zone completely. Since default costs are much higher than in the one-period debt case, even a small probability of pessimistic beliefs causing a default is too costly to risk. Both default frequency and spread volatility are zero.

In summary, there is an important commonality in outcomes between the long-term and one-period debt models. When calibrated to the same facts, the small probability of the concerned belief regime - and the accompanying overborrowing — significantly increases spread volatility in both models. In the Appendix we show that this commonality across one-period and long-term debt models holds up for the Italian case as well. We note that in all cases of the long-term bond model, buybacks of debt never happen or are extremely rare.

\section{Conclusion}

In this paper, we show that uncertainty between an auction and the next payment opens the door to a rich taxonomy of crises. In particular, we extend the nature of self-fulfilling crises to include bond issuances at fire-sale prices during a rollover crisis. This was motivated by the fact that crises in practice are often associated with positive issuances at abnormally high spreads. If creditors coordinate on such short-term uncertainty, then the government has an incentive to completely eliminate intra-period risk by adjusting the amount of debt auctioned. This distortion generates a large increase in the volatility of spreads, in both a one-period and a long-term bond model. The nature of "concerned" beliefs and the associated equilibrium behavior provide a novel lens to interpret the interest rate spikes and debt dynamics observed

similar shapes to the one-period model depicted in Figures 5 and 6. On part of the domain, the concerned belief price schedule is strictly lower than the optimistic schedule, tracking the interior price. In accordance with Proposition 6, the equilibrium price is invariant to beliefs for debt buy backs. For low levels of initial debt, debt issuance under the concerned regime is truncated, while we observe over borrowing near the ergodic mean.

${ }^{31}$ The fraction of defaults coincident and immediately following $\rho=C$ are $1.5 \%$ and $9.6 \%$ respectively. 
in recent sovereign debt crises.

\section{References}

Aguiar, Mark and Gita Gopinath, "Defaultable Debt, Interest Rate and the Current Account," Journal of International Economics, 2006, 69 (1), 64-83.

_ and _ , "Emerging Market Business Cycles: The Cycle Is the Trend," Journal of Political Economy, 2007, 115 (1), 69-102.

- and Manuel Amador, "Take the Short Route: How to Repay and Restructure Sovereign Debt with Multiple Maturities," Working Paper No. 19717, National Bureau of Economic Research, 2013.

_ and _ , "Sovereign Debt," in Gita Gopinath, Elhanan Helpman, and Kenneth Rogoff, eds., Handbook of International Economics, Vol. 4, North-Holland Elsevier, 2014, pp. 647687.

_ and _ , "A Contraction for Sovereign Debt Models," working paper, 2019.

_ and _ , "Self-Fulfilling Debt Dilution: Maturity and Multiplicity in Debt Models," American Economic Review, 2020, 110 (9), 2783-2818.

_ , _ , Emmanuel Farhi, and Gita Gopinath, "Coordination and Crisis in Monetary Unions," Quarterly Journal of Economics, 2015, 130 (4), 1727-1779.

_, _, Hugo Hopenhayn, and Ivan Werning, "Take the Short Route: Equilibrium Default and Debt Maturity," Econometrica, 2019, 87 (2), 423-462.

_ , Satyajit Chatterjee, Harold L. Cole, and Zachary R. Stangebye, "Quantitative Models of Sovereign Debt," in John Taylor and Harald Uhlig, eds., Handbook of Macroeconomics, Vol. 2, North-Holland Elsevier, 2016, pp. 1697-1755.

Arellano, Cristina, "Default Risk and Income Fluctuations in Emerging Economies," American Economic Review, 2008, 98 (3), 690-712.

- and Ananth Ramanarayanan, "Default and the Maturity Structure in Sovereign Bonds," Journal of Political Economy, 2012, 120 (2), 187-232.

Auclert, Adrien and Matthew Rognlie, "Unique Equilibrium in the Eaton-Gersovitz Model of Sovereign Debt," Journal of Monetary Economics, 2016, 84, 134-146.

Ayres, Joao, Gaston Navarro, Juan Pablo Nicolini, and Pedro Teles, "Sovereign Default: The Role of Expectations," 2015. Federal Reserve Bank of Minneapolis Working Paper 723.

Bocola, Luigi and Alessandro Dovis, "Self-Fulfilling Debt Crises: A Quantitative Analysis," American Economic Review, 2019, 109 (12), 4343-77. 
Calvo, Guillermo, "Servicing the Public Debt: The Role of Expectations," American Economic Review, 1988, 78 (4), 647-661.

Chatterjee, Satyajit and Burcu Eyigungor, "Maturity, Indebtedness, and Default Risk," American Economic Review, 2012, 102 (6), 2674-2699.

_, Dean Corbae, Kyle Dempsey, and Jose-Victor Rios-Rull, "A Quantitative Theory of the Credit Score," Working Paper No. 20-39, Federal Reserve Bank of Philadelphia, 2020.

Cole, Harold L. and Timothy J. Kehoe, “A Self-Fulfilling Model of Mexico's 1994-1995 Debt Crisis," Journal of International Economics, 1996, 41 (3-4), 309-330.

_ and _ , "Self-Fulfilling Debt Crises," Review of Economic Studies, 2000, 6r7 (1), 91-116.

Conesa, Juan Carlos and Timothy J. Kehoe, "Gambling for Redemption and SelfFulfilling Debt Crises," working paper, 2011.

Eaton, Jonathan and Mark Gersovitz, "Debt with Potential Repudiation: Theoretical and Empirical Analysis," Review of Economic Studies, 1981, 48 (2), 289-309.

- and Raquel Fernandez, "Sovereign Debt," in Gene Grossman and Kenneth Rogoff, eds., Handbook of International Economics, Vol. 3, North-Holland Elsevier, 1995, pp. 20312077.

Harsanyi, John C., "Games with Randomly Disturbed Payoffs: A New Rationale for Mixed-Strategy Equilibrium Points," International Journal of Game Theory, 1973, 2 (1), $1-23$.

Hatchondo, Juan Carlos and Leonardo Martinez, "Long-Duration Bonds and Sovereign Defaults," Journal of International Economics, 2009, 79 (1), 117-125.

Kaminsky, Graciela L., Carmen M. Reinhart, and Carlos A. Végh, "When It Rains, It Pours: Procyclical Capital Flows and Macroeconomic Policies," NBER Macroeconomics Annual, 2004, 19, 11-53.

Leland, Hayne, "Bond Prices, Yield Spreads, and Optimal Capital Structure with Default Risk," 1994. IBER Finance Working Paper 240.

Lorenzoni, Guido and Ivan Werning, "Slow Moving Debt Crises," July 2013. NBER Working Paper 19228.

Stangebye, Zachary R., "Beliefs and Long-Maturity Debt," Journal of International Economics, 2020, $12 \%$.

Tomz, Michael and Mark Wright, "Empirical Research on Sovereign Debt and Default," Annual Reviews of Economics, 2013, 5, 247-272.

Whitt Jr., Joseph A., "The Mexican Peso Crisis," Economic Review, Federal Reserve Bank of Atlanta, 1996, 81 (1), 1-20. 


\section{Online Appendix}

\section{Appendix A Proofs}

\section{A.1 Derivation of equation (4)}

The government's problem is to choose $B^{\prime} \in(-\infty, \bar{B}]$ to maximize the expected end-of-period value, where expectation is over the realization of $\epsilon$ :

$$
\begin{aligned}
V_{1}(s) & =\max _{B^{\prime}}\left\{F\left(\sigma^{-1} \Delta\left(s, B^{\prime}\right)\right) V^{R}\left(s, B^{\prime}\right)+\int_{\sigma^{-1} \Delta\left(s, B^{\prime}\right)}^{1}\left[V^{D}\left(s, B^{\prime}\right)+\sigma \epsilon\right] d F(\epsilon)\right\} \\
& =\max _{B^{\prime}}\left\{V^{D}\left(s, B^{\prime}\right)+F\left(\sigma^{-1} \Delta\left(s, B^{\prime}\right)\right) \Delta\left(s, B^{\prime}\right)+\sigma \int_{\sigma^{-1} \Delta\left(s, B^{\prime}\right)}^{1} \epsilon d F(\epsilon)\right\} .
\end{aligned}
$$

Using integration by parts, we can re-write this as (4).

\section{A.2 Proof of Proposition 1}

Proof. Let us define $H:[0,1] \rightarrow \mathbb{R}$ by

$$
\begin{aligned}
H(\epsilon) \equiv & u\left(Y-B+F(\epsilon) q_{E G}\left(B^{\prime}\right) B^{\prime}\right)-u\left(Y+F(\epsilon) q_{E G}\left(B^{\prime}\right) B^{\prime}\right)-\sigma \epsilon \\
& +\beta \mathbb{E}\left[V\left(s^{\prime}\right) \mid B^{\prime}\right]-\beta \underline{V}^{D} .
\end{aligned}
$$

Equation (13) is satisfied at $\tilde{\epsilon}$ if and only if $H(\tilde{\epsilon})=0$. Note that $\epsilon$ only enters $H$ via the functions $u$ and $F$, both of which are continuous. Hence, $H$ is continuous. Premise $(i)$ states that $H(1) \geq 0$. Premise $(i i)$ states that $H(0) \leq 0$. By continuity there is at least one $\epsilon \in[0,1]$ such that $H(\epsilon)=0$. If $H(1)>0$ and $H(0)<0$, then the $\epsilon$ that solves $H(\epsilon)=0$ must be strictly interior.

\section{A.3 Proof of Proposition 2}

Proof. For a given $\left(Y, B, B^{\prime}\right)$, let $q_{E G}$ denote $q_{E G}\left(B^{\prime}\right)$. If $q_{E G}=0$, the only equilibrium price is zero. If $B^{\prime} \leq 0$, the only equilibrium price is $q_{E G}=R^{-1}$, as assets always trade at the risk-free price. Thus the proposition is trivially true for $B^{\prime} \leq 0$ and $q_{E G}=0$. Henceforward, assume $q_{E G} B^{\prime}>0$.

Define the function $g:[0,1] \rightarrow \mathbb{R}$ by:

$$
g(\epsilon) \equiv u\left(Y-B+F(\epsilon) q_{E G} B^{\prime}\right)-u\left(Y+F(\epsilon) q_{E G} B^{\prime}\right)+\beta \mathbb{E}\left[V\left(s^{\prime}\right) \mid B^{\prime}\right]-\beta \underline{V}^{D} .
$$

Then $H:[0,1] \rightarrow \mathbb{R}$ defined in equation (17) in the proof of Proposition 1 can be written as:

$$
H(\epsilon) \equiv g(\epsilon)-\sigma \epsilon .
$$

Zero is an equilibrium if and only if $H(0) \leq 0 ; q_{E G}$ is an equilibrium price if and only if $H(1) \geq 0$; and $\tilde{\epsilon}$ solves equation (13) if and only if $H(\tilde{\epsilon})=0$. We consider the cases of $B<0, B=0$, and $B>0$ in turn: If $\boldsymbol{B}<\mathbf{0}$ : If $B<0$, then $g(\epsilon)>0$ for all $\epsilon \in[0,1]$. This uses the fact that $\beta \mathbb{E}\left[V\left(s^{\prime}\right) \mid B^{\prime}\right]-\beta \underline{V}^{D} \geq 0$. This inequality follows from the fact that $V(s) \geq \max _{B^{\prime}<\bar{B}} \mathbb{E}\left[V^{D}\left(s, B^{\prime}\right)+\sigma \epsilon\right] \geq \underline{V^{D}}$. As $g$ is continuous on the compact domain $[0,1]$, it achieves a minimum $\underline{g} \equiv \min _{\epsilon \in[0,1]} g(\epsilon)>0$. If $\sigma<\underline{g}$, then $H(\epsilon)=g(\epsilon)-\sigma \epsilon \geq$ $g-\sigma \epsilon>\sigma(1-\epsilon) \geq 0$. Hence, $H(\epsilon)>0$ for all $\epsilon$, and $q_{E G}\left(B^{\prime}\right)$ is the only possible equilibrium price. Thus, the proposition holds for $B<0$ by setting $K=\underline{g}>0$.

If $\boldsymbol{B}=\mathbf{0}$ : If $B=0$, then $g(\epsilon)=\beta \mathbb{E}\left[V\left(s^{\prime}\right) \mid B^{\prime}\right]-\beta \underline{V}^{D}$, which is independent of $\epsilon$. If $g=0$, then $H(\epsilon)=-\sigma \epsilon$, and the only possible equilibrium price is 0 for any $\sigma>0$. If $g>0$, then, letting $K=g>0$, for $\sigma<K$, we have $H(\epsilon)=K-\sigma \epsilon>0$. In this case, $H(\epsilon) \geq H(1)>0$ and the only possible price is 
$q_{E G}$. Thus, the proposition holds for $B=0$.

If $\boldsymbol{B}>0$ : If $B>0$, then concavity of $u$ implies that $g(\epsilon)$ is strictly increasing in $\epsilon$. In particular,

$$
g^{\prime}(\epsilon)=\left[u^{\prime}\left(Y-B+F(\epsilon) q_{E G} B^{\prime}\right)-u^{\prime}\left(Y+F(\epsilon) q_{E G} B^{\prime}\right)\right] F^{\prime}(\epsilon) q_{E G} B^{\prime}>0,
$$

where the last inequality uses the fact that $F^{\prime}(\epsilon) \geq \alpha>0$ and $q_{E G} B^{\prime}>0$. Let

$$
K \equiv \min _{\epsilon \in[0,1]}\left[u^{\prime}\left(Y-B+F(\epsilon) q_{E G} B^{\prime}\right)-u^{\prime}\left(Y+F(\epsilon) q_{E G} B^{\prime}\right)\right] \underline{f} q_{E G} B^{\prime}>0
$$

where the minimum exists, as $u^{\prime}$ is a continuous function and is strictly positive given that $g^{\prime}(\epsilon)>0$ for all $\epsilon \in[0,1]$. Then $H^{\prime}(\epsilon)=g^{\prime}(\epsilon)-\sigma \geq K-\sigma$. If $\sigma<K$, then $H^{\prime}(\epsilon)>0$. Hence there is at most one $\tilde{\epsilon}$ such that $H(\tilde{\epsilon})=0$. If $H(0) \leq 0 \leq H(1)$, then $\left\{0, q_{E G}, F(\tilde{\epsilon}) q_{E G}\right\}$ are all equilibrium prices. If $H(1)>H(0)>0$, then only $q_{E G}$ is an equilibrium price. If $H(0)<H(1)<0$, then only zero is an equilibrium price. Thus, the proposition holds for $B>0$.

\section{A.4 Proof of Proposition 3}

Proof. Using $H$ defined by (17) in the proof of Proposition 1, we have $\tilde{q}=0$ satisfies (8) if $H(0) \leq 0$; $\tilde{q}=q_{E G}\left(B^{\prime}\right)$ if $H(1) \geq 0$; and $\tilde{q} \in\left(0, q_{E G}\left(B^{\prime}\right)\right)$ if $H(\tilde{\epsilon})=0$ for some $\tilde{\epsilon} \in(0,1)$. Define

$$
h(x) \equiv u(Y-B+x)-u(Y+x) .
$$

We have

$$
H^{\prime}(\epsilon)=h^{\prime}\left(F(\epsilon) q_{E G}\left(B^{\prime}\right) B^{\prime}\right) F^{\prime}(\epsilon) q_{E G}\left(B^{\prime}\right) B^{\prime}-\sigma .
$$

By definition of $h$,

$$
\begin{aligned}
h^{\prime}(x) & =u^{\prime}(Y-B+x)-u^{\prime}(Y+x) \\
h^{\prime \prime}(x) & =u^{\prime \prime}(Y-B+x)-u^{\prime \prime}(Y+x) .
\end{aligned}
$$

As $B>0$ and $u$ is strictly concave, we have $h^{\prime}(x)>0$ for $x \geq 0$. If $u^{\prime \prime}$ is strictly increasing, then $h^{\prime \prime}(x)<0$. Hence, as $\epsilon$ increases, $h^{\prime}\left(F(\epsilon) q_{E G}\left(B^{\prime}\right) B^{\prime}\right)$ strictly decreases and $F^{\prime}(\epsilon)$ weakly decreases. As both are positive, their product decreases and $H^{\prime}$ is strictly decreasing. This establishes that there are at most two roots to $H$; that is, there are at most two interior prices that satisfy (13). If $H(0) \leq 0$, then $\tilde{q}=0$ satisfies (8), and there are at most three possible equilibrium prices, two of which are interior. If $H(0)>0$, then $\tilde{q}=0$ is not an equilibrium. As $H(0)>0$ and $H^{\prime}$ is strictly decreasing, there is at most one interior solution $\tilde{\epsilon}$ to $(13)$, with $H^{\prime}(\tilde{\epsilon})<0$. If there is such a $\tilde{\epsilon}<1$, then $H(1)<0$ and $\tilde{q}=F(\tilde{\epsilon}) q_{E G}\left(B^{\prime}\right)$ is the only equilibrium price. Otherwise, $H(\epsilon) \geq 0$ for all $\epsilon \in[0,1]$, and $\tilde{q}=q_{E G}\left(B^{\prime}\right)$ is the only equilibrium price.

\section{A.5 Proof of Proposition 4}

Proof. We first establish that $\mathbb{E}\left[V\left(s^{\prime}\right) \mid B^{\prime}\right] \geq \underline{V}^{D}+\sigma \mathbb{E} \epsilon$ for all $B^{\prime}$. To see this, it is always feasible to issue zero new debt and default with probability one on maturing debt:

$$
\begin{aligned}
V(s) & \geq u(Y)+\sigma \mathbb{E} \epsilon+\beta \underline{V}^{D} \\
& =\sigma \mathbb{E} \epsilon+u(Y)-\mathbb{E} u\left(Y^{\prime}\right)+\underline{V}^{D},
\end{aligned}
$$

where the second line uses the fact that $\underline{V}^{D} \equiv \mathbb{E} u\left(Y^{\prime}\right) /(1-\beta)$. Taking expectation over $s^{\prime}$ for any $B^{\prime} \leq \bar{B}$, we have

$$
\mathbb{E}\left[V\left(s^{\prime}\right) \mid B^{\prime}\right] \geq \underline{V}^{D}+\sigma \mathbb{E} \epsilon .
$$


From the definitions of $V_{C K}^{R}$ and $V_{C K}^{D}$, we can re-write $\mathbb{B}_{C K}$ as:

$$
\mathbb{B}_{C K}(Y, B) \equiv\left\{B^{\prime} \in[0, \bar{B}] \mid u(Y-B)-u(Y)+\beta \mathbb{E}\left[V\left(s^{\prime}\right) \mid B^{\prime}\right]-\beta \underline{V}^{D} \leq 0\right\} .
$$

Equation (22) implies that if $B^{\prime} \in \mathbb{B}_{C K}(Y, B)$, then

$$
\begin{aligned}
0 & \geq u(Y-B)-u(Y)+\beta \mathbb{E}\left[V\left(s^{\prime}\right) \mid B^{\prime}\right]-\beta \underline{V}^{D} \\
& \geq u(Y-B)-u(Y)+\beta \sigma \mathbb{E} \epsilon .
\end{aligned}
$$

That is, (14) is a necessary condition for $\mathbb{B}_{C K} \neq \emptyset$. To show that (14) is also a sufficient condition, suppose (14) is satisfied. For $B^{\prime}$ larger than the natural borrowing limit (which we have assumed is strictly less than $\bar{B}$ ), repayment is infeasible for any endowment realization and default occurs with probability one. Hence, there exists a $\tilde{B} \in(0, \bar{B})$ such that $\mathbb{E}\left[V\left(s^{\prime}\right) \mid B^{\prime} \geq \tilde{B}\right]=\sigma \mathbb{E} \epsilon+\underline{V}^{D}$. Therefore, $[\tilde{B}, \bar{B}] \subset \mathbb{B}_{C K}(Y, B)$. As $[\tilde{B}, \bar{B}] \neq \emptyset$ when (14) holds, $\mathbb{B}_{C K}$ is not empty.

\section{A.6 Proof of Proposition 5}

Proof. If $q\left(s, B_{i}^{\prime}\right)$ is interior for $i=1,2$, there exist respective $\tilde{\epsilon}_{i}$ that satisfy (13). As $q\left(s, B_{i}^{\prime}\right) / q_{E} G\left(B_{i}^{\prime}\right)=$ $F\left(\tilde{\epsilon}_{i}\right)$, and $F$ is strictly increasing on its support, we have $\tilde{\epsilon}_{1} \leq \tilde{\epsilon}_{2}$. By (13), we also have:

$$
V^{R}\left(s, B_{i}^{\prime}\right)=V^{D}\left(s, B_{i}^{\prime}\right)+\sigma \tilde{\epsilon}_{i},
$$

for $i=1,2$. Using this, the expected payoff from $B_{i}^{\prime}$ at the time of auction can be written:

$$
\begin{aligned}
& \mathbb{E} \max \left\{V^{R}\left(s, B_{i}^{\prime}\right), V^{D}\left(s, B_{i}^{\prime}\right)+\sigma \tilde{\epsilon}\right\} \\
& =\mathbb{E} \max \left\{V^{D}\left(s, B_{i}^{\prime}\right)+\sigma \tilde{\epsilon}_{i}, V^{D}\left(s, B_{i}^{\prime}\right)+\sigma \epsilon\right\} \\
& =V^{D}\left(s, B_{i}^{\prime}\right)+\sigma \mathbb{E} \max \left\{\tilde{\epsilon}_{i}, \epsilon\right\} .
\end{aligned}
$$

As $q\left(s, B_{1}^{\prime}\right) B_{1}^{\prime} \leq q\left(s, B_{2}^{\prime}\right) B_{2}^{\prime}$, we have $V^{D}\left(s, B_{1}^{\prime}\right) \leq V^{D}\left(s, B_{2}^{\prime}\right)$. This, plus the fact that $\tilde{\epsilon}_{1} \leq \tilde{\epsilon}_{2}$ implies that $B_{2}^{\prime}$ weakly dominates $B_{1}^{\prime}$ as a debt choice. If either $q\left(s, B_{1}^{\prime}\right) B_{1}^{\prime}<q\left(s, B_{2}^{\prime}\right) B_{2}^{\prime}$ or $\tilde{\epsilon}_{1}<\tilde{\epsilon}_{2}$, the preference for $B_{2}^{\prime}$ is strict.

\section{A.7 Proof of Proposition 6}

Proof. Fix $s$ and $B^{\prime}<(1-\lambda) B$ and let $q_{E G}$ denote $q_{E G}\left(s, B^{\prime}\right)$. For $\tilde{q} \in\left[0, q_{E G}\right]$, define $\hat{F}(\tilde{q})$ by:

$\hat{F}(\tilde{q}) \equiv$

$F\left(\frac{1}{\sigma}\left[u\left(Y-\left(r^{*}+\lambda\right) B+\tilde{q} \times\left[B^{\prime}-(1-\lambda) B\right]\right)-u\left(Y+\tilde{q} \times\left[B^{\prime}-(1-\lambda) B\right]\right)+\beta \mathbb{E}\left[V\left(s^{\prime}\right) \mid s, B^{\prime}\right]-\beta \mathbb{E} V^{D}\left(s^{\prime}\right)\right]\right)$.

A $\tilde{q} \in\left[0, q_{E G}\right]$ is an equilibrium price if and only if $\tilde{q} / q_{E G}=\hat{F}(\tilde{q})$. Note that $\hat{F}$ maps $\left[0, q_{E G}\right]$ into $[0,1]$, is weakly decreasing (as $B^{\prime}<(1-\lambda) B$ ), and is continuous. Hence, there exists one and only one $\tilde{q}$ that satisfies the equilibrium condition.

\section{A.8 Proof of Proposition 7}

Proof. Since $q\left(s, B_{i}^{\prime}\right)$ are interior equilibrium prices for $i=1,2$, there exist thresholds $\tilde{\epsilon}_{i} \in[0,1]$ such that:

$$
V^{R}\left(s, B_{i}^{\prime}\right)=V^{D}\left(s, B_{i}^{\prime}\right)+\sigma \tilde{\epsilon}_{i}, \text { for } i=1,2 .
$$


Conditional on auctioning $B_{i}^{\prime}$, the expected payoff is:

$$
\begin{aligned}
& \int_{0}^{1} \max \left\{V^{R}\left(s, B_{i}^{\prime}\right), V^{D}\left(s, B_{i}^{\prime}\right)+\sigma \epsilon\right\} d F(\epsilon) \\
& =\int_{0}^{1} \max \left\{V^{D}\left(s, B_{i}^{\prime}\right)+\sigma \tilde{\epsilon}_{i}, V^{D}\left(s, B_{i}^{\prime}\right)+\sigma \epsilon\right\} d F(\epsilon) \\
& =V^{D}\left(s, B_{i}^{\prime}\right)+\sigma \int_{0}^{1} \max \left\{\tilde{\epsilon}_{i}, \epsilon\right\} d F(\epsilon) .
\end{aligned}
$$

From condition (i) in the proposition statement, we have $\tilde{\epsilon}_{1} \geq \tilde{\epsilon}_{2}$, with strict inequality if (i) is strict. As the default value is increasing in net auction revenue, from premise (ii) in the proposition, we have $V^{D}\left(s, B_{1}^{\prime}\right) \geq V^{D}\left(s, B_{2}^{\prime}\right)$, with strict inequality if (ii) is strict. Thus, the expected value from auctioning $B_{1}^{\prime}$ is weakly greater than $B_{2}^{\prime}$, and strictly if either (i) or (ii) is strict.

Proof. Since $q\left(s, B_{i}^{\prime}\right)$ are interior equilibrium prices for $i=1,2$, there exist thresholds $\tilde{\epsilon}_{i} \in[0,1]$ such that:

$$
V^{R}\left(s, B_{i}^{\prime}\right)=V^{D}\left(s, B_{i}^{\prime}\right)+\sigma \tilde{\epsilon}_{i}, \text { for } i=1,2 .
$$

Conditional on auctioning $B_{i}^{\prime}$, the expected payoff is:

$$
\begin{aligned}
& \int_{0}^{1} \max \left\{V^{R}\left(s, B_{i}^{\prime}\right), V^{D}\left(s, B_{i}^{\prime}\right)+\sigma \epsilon\right\} d F(\epsilon) \\
& =\int_{0}^{1} \max \left\{V^{D}\left(s, B_{i}^{\prime}\right)+\sigma \tilde{\epsilon}_{i}, V^{D}\left(s, B_{i}^{\prime}\right)+\sigma \epsilon\right\} d F(\epsilon) \\
& =V^{D}\left(s, B_{i}^{\prime}\right)+\sigma \int_{0}^{1} \max \left\{\tilde{\epsilon}_{i}, \epsilon\right\} d F(\epsilon) .
\end{aligned}
$$

From condition (i) in the proposition statement, we have $\tilde{\epsilon}_{1} \geq \tilde{\epsilon}_{2}$, with strict inequality if (i) is strict. As the default value is increasing in net auction revenue, from premise (ii) in the proposition, we have $V^{D}\left(s, B_{1}^{\prime}\right) \geq V^{D}\left(s, B_{2}^{\prime}\right)$, with strict inequality if (ii) is strict. Thus, the expected value from auctioning $B_{1}^{\prime}$ is weakly greater than $B_{2}^{\prime}$, and strictly if either (i) or (ii) is strict.

\section{Appendix B Mixed Strategy Equilibria: $\sigma=0$}

In this appendix, we formalize the notion that as $\sigma \rightarrow 0$, the equilibrium converges to a mixedstrategy equilibrium in which the government randomizes over default or repayment. That is, suppose the government's decision at settlement is to pick a probability of repayment: $p \in[0,1]$. When facing a price $\tilde{q}$, the government's best response is:

$$
\begin{aligned}
& p=1 \text { if } u\left(Y-B+\tilde{q} B^{\prime}\right)+\beta \mathbb{E}\left[V\left(s^{\prime}\right) \mid B^{\prime}\right]>u\left(Y+\tilde{q} B^{\prime}\right)+\beta \underline{V}^{D} ; \\
& p=0 \text { if } u\left(Y-B+\tilde{q} B^{\prime}\right)+\beta \mathbb{E}\left[V\left(s^{\prime}\right) \mid B^{\prime}\right]<u\left(Y+\tilde{q} B^{\prime}\right)+\beta \underline{V}^{D} ; \text { and } \\
& p \in[0,1] \text { if } u\left(Y-B+\tilde{q} B^{\prime}\right)+\beta \mathbb{E}\left[V\left(s^{\prime}\right) \mid B^{\prime}\right]=u\left(Y+\tilde{q} B^{\prime}\right)+\beta \underline{V}^{D} .
\end{aligned}
$$

Similarly, the lenders' best response to an anticipated $p$ at settlement is to bid $\tilde{q}=p \times q_{E G}$ at auction. A mixed-strategy equilibrium price is a pair $(p, \tilde{q})$ that satisfies $\tilde{q}=p q_{E G}$ and equation (24). Following the steps behind Proposition 1, it is straightforward to see that if $\left(p=1, \tilde{q}=q_{E G}\right)$ satisfies the first inequality in (24), and $(p=0, \tilde{q}=0)$ satisfies the second, then there is also a unique $p \in(0,1)$ with an interior $\tilde{q}=p q_{E G} \in\left(0, q_{E G}\right)$ that satisfies the third line of $(24)$.

Reminiscent of Harsanyi (1973) purification, the mixed strategy price is the limit of the pure- 
strategy interior price as $\sigma \rightarrow 0$ :

Proposition A.1. Given $\left(Y, B, B^{\prime}\right)$ with $B^{\prime}>0$, suppose $V_{E G}^{R}\left(Y, B, B^{\prime}\right)>V_{E G}^{D}\left(Y, B^{\prime}\right)$ and $V_{C K}^{R}\left(Y, B, B^{\prime}\right)<$ $V_{C K}^{D}(Y)$. Let $\sigma_{n}$ be a monotone decreasing sequence converging to zero. Then there exist an integer $N<\infty$ and a sequence $\tilde{\epsilon}_{n}$ satisfying (13) for each $\sigma_{n}$ for $n>N$. Moreover, $p=\lim _{n \rightarrow \infty} F\left(\tilde{\epsilon}_{n}\right)$ and $\tilde{q}=\lim _{n \rightarrow \infty} F\left(\tilde{\epsilon}_{n}\right) q_{E G}\left(B^{\prime}\right)$ exist and satisfy (24).

Proof. First, note that $B \neq 0$. To see this, when $B=0$, we have

$$
V_{E G}^{R}\left(Y, 0, B^{\prime}\right)-V_{E G}^{D}(Y)=\beta\left(\mathbb{E} V\left(s^{\prime}\right)-\underline{V}^{D}\right)=V_{C K}^{R}\left(Y, 0, B^{\prime}\right)-V_{C K}^{D}(Y),
$$

which is inconsistent with the inequalities in the proposition's premise. Hence, we take $B^{\prime} \neq 0$ in what follows. As $\left(Y, B, B^{\prime}\right)$ is fixed throughout, we drop these arguments from the notation below. The premise implies $V_{E G}^{R}>V_{C K}^{R}$, and hence it must be the case that $q_{E G}>0$.

Define $h:[0,1] \rightarrow \mathbb{R}$ by:

$$
h(x) \equiv u\left(Y-B+x q_{E G} B^{\prime}\right)-u\left(Y+x q_{E G} B^{\prime}\right) .
$$

$h$ represents the net current period flow utility from repayment over default when the price is $x q_{E G}$. By strict concavity of $u$ and $q_{E G} B^{\prime}>0$, we have $h^{\prime}(x) \gtrless 0$ when $B \gtrless 0$. The inequalities in the premise imply:

$$
h(1)+\beta\left(\mathbb{E} V\left(s^{\prime}\right)-\underline{V}^{D}\right)>0>h(0)+\beta\left(\mathbb{E} V\left(s^{\prime}\right)-\underline{V}^{D}\right) .
$$

By continuity of $h$, there exists a $p \in[0,1]$ such that $h(p)+\beta\left(\mathbb{E} V\left(s^{\prime}\right)-\underline{V}^{D}\right)=0$. At price $\tilde{q}=p q_{E G}$, the government is indifferent to defaulting or repaying when $\sigma=0$. At price $\tilde{q}$ and if the government randomizes by defaulting with probability $1-p$, the lenders break even. Hence, $(\tilde{q}, p)$ is a mixed strategy equilibrium.

Let $K>0$ be defined as in Proposition 2. Let $\bar{\sigma} \equiv V_{E G}^{R}-V_{E G}^{D}$, which is strictly positive by the proposition's premise. Let $N$ be defined by:

$$
N \equiv \inf \left\{n \geq 0 \mid \sigma_{n}<\min \{\bar{\sigma}, K\}\right\} .
$$

As the sequence $\sigma_{n}$ is monotonically decreasing, for $n>N$, we have

$$
V_{E G}^{R}-V_{E G}^{D}-\sigma_{n}>V_{E G}^{R}-V_{E G}^{D}-\bar{\sigma}=0,
$$

and hence $q_{E G}$ is supportable as an equilibrium price. As $V_{C K}^{R}<V_{C K}^{D}$, zero is also an equilibrium price. For each $n>N$ and associated $\sigma_{n}$, by Proposition 2, there exists a unique $\epsilon_{n}$ such that equation (13) holds. Define $p_{n} \equiv F\left(\epsilon_{n}\right)$. From (13) and the fact that $\tilde{\epsilon}_{n} \leq 1$, we have

$$
0 \leq h\left(p_{n}\right)-h(p)=\sigma_{n} \tilde{\epsilon}_{n} \leq \sigma_{n} .
$$

Hence, as $\sigma_{n} \rightarrow 0, h\left(p_{n}\right)-h(p) \rightarrow 0$. To establish convergence in the arguments of $h$, define

$$
\kappa \equiv \min _{x \in[0,1]}\left|h^{\prime}(x)\right| .
$$

As $h^{\prime}$ is continuous and $h^{\prime}$ is either strictly positive or negative for all $x \in[0,1]$ given $B \neq 0, \kappa>0$ is well defined. Note that by definition

$$
h\left(p_{n}\right)-h(p) \geq \kappa\left|p_{n}-p\right| .
$$

Hence, $h\left(p_{n}\right)-h(p) \rightarrow 0$ implies $\left|p_{n}-p\right| \rightarrow 0$. 


\section{Appendix C Further Numerical Experiments}

Several additional numerical experiments to further examine the implications of our model are reported here.

\section{C.1 Italy Calibration}

Using real GDP from 1960Q1-2020Q3, ${ }^{32}$ we estimate the same process for endowment as reported for Mexico in the text. The estimated parameters are: $\mu_{g}=0.002, \rho_{g}=0.579, \sigma_{g}=0.008$, and $\sigma_{z}=0.0097$.

For 2011, tax revenue net of social security contributions was 474,863 million euros, which was $29.0 \%$ of GDP. ${ }^{33}$ The replication data provided by Bocola and Dovis (2019) reports that 373,000 million euros of debt was scheduled to come due in the year following 2011Q4. Debt payments as a ratio of tax revenues net of social security contributions thus totaled $78.5 \%$ and the face value of total debt securities relative to tax revenue was 334\% (or 97\% of GDP). 2011Q4 represented a debt burden relative to tax revenue that is the 93rd percentile of the Bocola-Dovis dataset. We therefore target debt payments of $78.5 \%$ of resources at the $93 \mathrm{rd}$ percentile of the model's ergodic distribution of debt. For the long-term model, to match the associated face value given a $3 \%$ coupon, we set $\lambda=0.0286$, or a maturity of roughly three years (35 quarters).

With regard to sovereign spreads, for the period 1999Q1-2020Q4 the spread between Italian and German five-year bonds had a standard deviation of $1.05 \% .^{34}$

We targeted the standard deviation of the spread and the ratio of debt payments to resources at the 93rd percentile, assuming $\beta=0.95$. For the one-period debt model, this requires $d=0.14$ and the probability of the concerned regime of $0.4 \%$ per quarter; for the long-term bond model, it requires $d=0.665$ and a probability of the concerned regime of $0.3 \%$ per quarter.

The model's moments are reported in Table 2. Italy has a less volatile output process, a higher level of the debt payment coming due, and a lower volatility of the spread than Mexico. When we calibrate the base model for both the one-period and long-term bond cases, we are able to hit these targets. When we only have $\rho=O$ beliefs, the default rate and the spread volatility essentially fall to zero with one-period bonds. In the long-term bond case with $\rho=O$ beliefs, the temptation to engage in debt dilution leads to almost as many defaults but substantially less volatility relative to the base case. Once again, the Cole-Kehoe version with one period debt and $\rho \in\{O, P\}$ generates a lot more default in the one-period bond case, but not much volatility, and essentially no defaults and no spread volatility with long-term bonds. All of these results mirror those found for Mexico.

\section{C.2 Partial Retention of Auction Revenue}

Beyond allowing for long-term debt, another aspect of capturing sovereign debt crises is getting investor returns in default right. In Cole-Kehoe, it is assumed that the government can keep all of the proceeds of an auction, while Eaton-Gersovitz effectively assume that it can keep none. Viewed in terms of a quarterly period length, with weekly auctions, both assumptions seem extreme. This leads us to also consider the intermediate case with long-term debt where the government gets to keep $1 / 2$ of the auction proceeds in the event of default, the rest being split pro-rata among the

\footnotetext{
${ }^{32}$ Italian data are from from OECD.stat (https://stats.oecd.org).

${ }^{33}$ Social security contributions were 211,637 million euros leading to total tax revenue of 686,500 million euros.

${ }^{34}$ The German and Italian data are 5-year yields from Deutsche Bundesbank and Banca D'Italia, respectively, as reported in Haver Analytics G10 summary statistics database.
} 
Table 2: Simulated Moments for Italy

\begin{tabular}{|c|c|c|c|c|}
\hline Model & $\begin{array}{c}93 \% \text { ile } \\
\text { DebtPmt/Rev } \\
\text { (Quarterly) }\end{array}$ & $\begin{array}{c}\text { Default } \\
\text { Frequency } \\
\text { (Annualized) } \\
\end{array}$ & $\begin{array}{c}\operatorname{StDev}\left(r-r^{*}\right) \\
\text { (Annualized) }\end{array}$ & $\frac{\operatorname{StDev}(\ln c)}{\operatorname{StDev}(\ln y)}$ \\
\hline & \multicolumn{4}{|c|}{ One-Period Bonds } \\
\hline Base, $\rho \in\{O, C\}$ & $79 \%$ & $0.1 \%$ & $1.1 \%$ & 1.11 \\
\hline Optimistic, $\rho \in\{O\}$ & $79 \%$ & $0.0 \%$ & $0.0 \%$ & 1.11 \\
\hline \multirow[t]{2}{*}{ Cole-Kehoe, $\rho \in\{O, P\}$} & $74 \%$ & $2.1 \%$ & $0.1 \%$ & 1.07 \\
\hline & \multicolumn{4}{|c|}{ Long-Term Bonds } \\
\hline Base, $\rho \in\{O, C\}$ & $79 \%$ & $0.9 \%$ & $1.1 \%$ & 1.41 \\
\hline Optimistic, $\rho \in\{O\}$ & $80 \%$ & $0.8 \%$ & $0.5 \%$ & 1.44 \\
\hline Cole-Kehoe, $\rho \in\{O, P\}$ & $53 \%$ & $0.0 \%$ & $0.0 \%$ & 1.50 \\
\hline
\end{tabular}

Table 3: Long-Term Model Moments with Partial Retention

\begin{tabular}{lcccc}
\hline \hline & $\begin{array}{c}97 \% \text { ile } \\
\text { DebtPmt/Rev } \\
\text { (Quarterly) }\end{array}$ & $\begin{array}{c}\text { Default } \\
\text { Frequency } \\
\text { (Annualized) }\end{array}$ & $\begin{array}{c}\text { StDev }\left(r-r^{*}\right) \\
\text { (Annualized) }\end{array}$ & $\begin{array}{c}\text { StDev(lnc) } \\
\text { StDev(lny) }\end{array}$ \\
\hline Base, $\rho \in\{O, C\}$ & $66 \%$ & $5.8 \%$ & $2.3 \%$ & 1.51 \\
Optimistic, $\rho=O$ & $67 \%$ & $5.3 \%$ & $1.1 \%$ & 1.54 \\
Cole-Kehoe, $\rho \in\{O, P\}$ & $37 \%$ & $0.0 \%$ & $0.0 \%$ & 1.41 \\
\hline
\end{tabular}

government's creditors (old and new) under the assumption that the auction revenue is not repatriated until all outstanding claims are settled. The assumption that bondholders receive payments (if any) in proportion to the face value of their claims reflects the pari passu and acceleration clauses typically included in sovereign bond contracts.

When we calibrate the model to our two Mexican moments, with maturity set to be the same as in the long-term case and with the retention set to $1 / 2$, we find that $d=0.455$ and concerned probability of $0.25 \%$ quarterly. The results are reported in Table 3 and, strikingly, closely mirror the results (for the 100\% retention case) reported in the bottom panel of Table 1.

\section{C.3 Larger Interim Shocks}

To examine the sensitivity of our results to a larger volatility of the interim shock $\sigma$, we scaled the shock by a factor of 100 and recalculated the results for the original calibration for Mexico. The results are virtually unchanged relative to our baseline for Mexico.

\section{C.4 Alternate Timing Assumption: Eaton-Gersovitz}

In this section, we explore model predictions for the Eaton-Gersovitz timing, namely, the assumption that new debt can be issued only if old debt is paid off. This assumption effectively reverses the timing of the default decision and the auction. Since the shock to the default payoff comes 
Table 4: Base Model Moments with Larger Interim Shocks

\begin{tabular}{lcccc}
\hline \hline & $\begin{array}{c}97 \% \text { ile } \\
\text { DebtPmt/Rev } \\
\text { (Quarterly) }\end{array}$ & $\begin{array}{c}\text { Default } \\
\text { Frequency } \\
\text { (Annualized) }\end{array}$ & $\begin{array}{c}\operatorname{StDev}\left(r-r^{*}\right) \\
\text { (Annualized) }\end{array}$ & $\begin{array}{c}\operatorname{StDev}(\ln c) \\
\operatorname{StDev}(\ln y)\end{array}$ \\
\hline Short-Term & $64 \%$ & $0.4 \%$ & $2.3 \%$ & 1.16 \\
Long-Term & $66 \%$ & $5.3 \%$ & $2.2 \%$ & 1.51 \\
\hline
\end{tabular}

before the auction it is no longer an intraperiod shock, and given its small variance, it can be safely removed for the purpose of this exercise.

Table 5: Base Model Moments Under EG Timing

\begin{tabular}{lcccc}
\hline \hline & $\begin{array}{c}97 \% \text { ile } \\
\text { DebtPmt/Rev } \\
\text { (Quarterly) }\end{array}$ & $\begin{array}{c}\text { Default } \\
\text { Frequency } \\
\text { (Annualized) }\end{array}$ & $\begin{array}{c}\operatorname{StDev}\left(r-r^{*}\right) \\
(\text { Annualized) }\end{array}$ & $\begin{array}{c}\operatorname{StDev}(\ln c) \\
\operatorname{StDev}(\ln y)\end{array}$ \\
\hline Short-Term & $254 \%$ & $0.3 \%$ & $0.1 \%$ & 1.78 \\
Long-Term & $77 \%$ & $2.1 \%$ & $0.3 \%$ & 1.22 \\
\hline
\end{tabular}

The results, displayed in Table 5, show that in both the one-period and long-term debt cases, debt payments (and debt levels) rise substantially; in the one-period case, it rises by nearly an order of magnitude. The expansion in debt speaks to the importance of the commitment to use auction revenue for repayment of inherited debt implicit in the EG timing. But, aside from this, both default frequency and spread volatility fall to very low levels in the one-period debt case. While the long-term debt case generates a higher frequency of default, the volatility of spreads still remains quite low. These findings are consistent with what the literature finds if nonlinear default costs are ignored. Also, as shown in Aguiar et al. (2016), even allowing for the possibility of nonlinear default costs cannot deliver the observed spread volatility for Mexico. 